ISSN 1112-9867

\title{
SCANNING KELVIN PROBE APPLIED TO LOCALISED CORROSION
}

\author{
A. Hussain and Sk M. Haque \\ Department of Chemical Engineering and Process Technology, Jubail Industrial College, \\ P. O. Box. 10099, Al-Jubail, KSA.
}

Received: 19 October 2014 / Accepted: 12 January 2015 / Published online: 15 January 2015

\begin{abstract}
This paper focuses on specific applications of the SKP system. The instrument is calibrated, using different thickness of a model polymer Poly Vinyl Butyral (PVB) on mild steel and on galvanised steel. Artificial defects are used to show how the instrument is capable of detecting a localised corrosion cell and its ability to picture the delamination of the coating from the steel substrate. An industrial application is undertaken with the instrument, where epoxy coated galvanised steel; with an introduced defect in the coating and various added inhibitors. Chromates and chromate replacements have been studied.
\end{abstract}

Keywords: Scanning Kelvin probe; Poly Vinyl Butyral; Localised Corrosion; Epoxy Coating.

\section{INTRODUCTION}

The Scanning Kelvin Probe (SKP) is a non-contact, non-destructive instrument designed to measure the surface work function difference between conducting coated or semi-conducting materials and a metallic probe. The technique operates using a vibrating capacitance probe through a swept back potential, the work function difference is measured between the scanning probe reference tip and the sample surface. The work function can be directly correlated to the surface condition. A unique aspect of the SKP is its ability to make measurements in a humid or gaseous environment.

Author Correspondence, e-mail: hussain_a@jic.edu.sa

ICID: 1134458 
Chen et al [1] used a scanning Kelvin probe (SKP) to measure the potential distribution under a $0.5 \mathrm{M} \mathrm{NaCl}$ drop on AA2024. They found that the potential under the drop was lower than the surrounding areas and a minimum occurred at the center of the drop. In contrast, Nazarov and Thierry [2] applied the SKP technique to $0.01-0.1 \mathrm{M} \mathrm{NaCl}$ droplets on pure $\mathrm{Al}$ and found no cathodic area had formed. However under a $0.01 \mathrm{M} \mathrm{NaCl}+10^{-4} \mathrm{M} \mathrm{CuCl}_{2}$ pitting under the droplet was observed at the boundary with passive metal. Cathodic processes were accelerated by copper in solution and took place inside the deposition.

A recent study by Knight et al [3] showed the importance of alloy microstructure in the corrosion of AA2024-T351 under a NaCl drop. Corrosion was found to initiate at a cluster of intermetallic (IM) particles at the surface and to develop into a thin network of intergranular corrosion. With time the network penetrated deeper into the alloy and the corrosion pathways thickened.

The role of large constituent IM particles in corrosion $\mathrm{Al}-\mathrm{Cu}-\mathrm{Mg}$ alloys has been amply demonstrated in bulk solution [4]. It is worthwhile briefly exploring some of the key features of IM particle attack as background to the current droplet study. IM particles present a point of susceptibility since the oxide layer covering them may contain flaws or intrinsically offer less protection [5], while the electrochemical characteristics of the particles themselves often differ greatly from the surrounding aluminum matrix [6].

In aerated solutions, IM particles that are cathodic with respect to the matrix are frequently found to be surrounded by a thin, peripheral zone of matrix which has been dissolved. This type of localised attack is known as trenching. In the situation where these particles are isolated, then there is no further attack on the matrix. However, when the IM particles form clusters, then stable pitting can develop from the cluster. A number of studies suggest that this is as a result of excessive trenching causing large open pit sites [7-11]. More recent work, however, indicates that for some microstructures, the process initiates through $\mathrm{Cu}$-enrichment of the cluster via $\mathrm{S}$ phase dealloying and $\mathrm{Cu}$ plating on IM particles within the cluster, which raises the cathodic activity of the cluster and drives the anode into the surface through the grain boundary network [12-14]. In this model, grain etchout resulting in the formation of large open pits occurs at a later stage [15]. Several techniques with enhanced spatial resolution have been introduced recently to the field of corrosion science, with the advantages of giving information on the processes occurring locally at electrochemically active surfaces. The scanning kelvin probe (SKP) [16-20] has been quite successful. 


\section{EXPERIMENTAL}

\section{Preparation of Poly Vinyl Butyral samples}

Mild steel panels $(15 \mathrm{~mm}$ x $7 \mathrm{~mm}$ ) were used and degreased with acetone. The Poly Vinyl Butyral (M r 90000 - 120 000, Aldrich chemical company) was dissolved in ethanol and then cast on to the mild steel panel and allowed to air dry over a 24-hour period. Different thicknesses of PVB films were cast onto the mild steel panel. The dry PVB thickness was measured using an Elcometer gauge (256 FN B9). Artificial defects were introduced by drilling a hole with a diameter of $0.5 \mathrm{~mm}$ and a $1 \mathrm{~mm}$ in length scratch using a scalpel blade through the PVB layer into the substrate.

Edges etc, not coated by the PVB, were covered by beeswax. The PVB was also cast on to galvanised steel panels $(8 \times 15 \mathrm{~cm})$ thickness $1.2 \mathrm{~mm}$ and artificial defects introduced as for the mild steel substrate. A $20 \mathrm{~cm}$ length of nichrome wire was spot welded to a corner of the mild steel panel and a plastic sleeve covered the nichrome wire. The samples were placed into a corrosive solution (3.5\% NaCl solution). The samples were taken from the solution every 24 hours, left to air dry and scanned under the vibrating probe. The SKP scan parameters used for the experiments are given in Table -1 and subsequent scans were carried out using these parameters.

\section{Galvanised steel 'model' cut edge samples}

Model cells designed to show cut-edge corrosion were prepared. Coupons (58x17 mm) were cut from a sheet of Zinctec SO484. The sheet was $1.2 \mathrm{~mm}$ thick galvanised steel, with a layer of $15 \mu \mathrm{m}$ of zinc. A $20 \mathrm{~cm}$ length of nichrome wire was spot welded to one side of the coupon. The coupons were dipped in a two-pack epoxy (International Paints KBA 800, KBA 803); this was done to avoid crevice corrosion after mounting and thus, make sure that only the activity from the cut-edge was measured. The coupon was placed in a MetSet cylindrical mould (diameter $=25 \mathrm{~cm}$ ) and located in a vertical position by use of spacers; the nichrome wire was covered with a plastic sleeve and fed through a hole in the lid of the mould. The mould was then filled with epoxy resin and hardener and left for 24 hours to allow complete curing. Finally, the top surface of the cell was ground using 330, 400, 600, 800, and 1200 grade silicon carbide paper, and finally rinsed with de-ionised water and acetone.

The cell was placed into the sample holder of the environmental cell. The legs of the environmental cell were adjusted via a spirit level so that the surface of the sample was horizontal and flat. The legs of the instrument were also adjusted to make sure that the instrument was level and horizontal to the sample. This was achieved by using a spirit level 
placed at various points on the instrument. A square well was made over the cut edge using PVC tape and into this well was placed a small amount of artificial acid rainwater solution. The probe was brought close as possible to the meniscus and sent $50 \mu \mathrm{m}$ vertically up. SKP area scans were carried out every hour. Then using a fresh sample, a small amount of strontium chromate was added to the artificial acid rainwater solution in the well and again SKP area scans were carried out overtime.

Table 1: SKP parameters for cut edge studies.

Step scan mode

Tungsten wire probe

Probe height (average)

Vibration amplitude of the probe

Number of lines

Area scan (x)

Area scan (y)
$0.5 \mathrm{~mm}$

$50 \mu \mathrm{m}$

$25 \mu \mathrm{m}$

96

$8000 \mu \mathrm{m}$

$5500 \mu \mathrm{m}$

\section{Preparation of epoxy coat samples}

The epoxy coatings were based upon a two-pack clear epoxy composition produced by $\mathrm{H}$. Marcel Guest Ltd (Manchester, UK). The basis of the epoxy composition was a diane resin and amide hardener. The epoxy coatings were applied onto acetone degreased galvanised steel in two layers, an inhibitor - containing primer (dry-film thickness $30 \mu \mathrm{m}$ ) and topcoat (dry-film thickness $100 \mu \mathrm{m}$ ), using a drawbar technique. The size of the galvanised steel samples was 8 $\mathrm{x} 15 \mathrm{~cm}$; the thickness of the zinc coating was about $15 \mu \mathrm{m}$.

Different primer formulations were used, namely E7 $\left(\mathrm{TiO}_{2} 6 \mathrm{v} \%\right)$, E8 (Actirox /Shieldex 3/3 v\%), E16 (Actirox/Shieldex 7/11 v\%), E18 (Actirox/Shieldex 4/4v\%) and E17 (strontium chromate $1.5 \mathrm{v} \%)$. The pigments were separately introduced into the epoxy by mixing during 24 hours in a ceramic ball mill. Artificial defects were introduced by drilling a hole with a diameter of $0.5 \mathrm{~mm}$ through the organic and zinc coating layers. The coatings were cured for 24 hours at $20^{\circ} \mathrm{C}$ and post-cured in an oven for 6 hours at $60^{\circ} \mathrm{C}$. The SKP parameters are shown in Table 2 for the experiments. 
Table 2: SKP parameters for the epoxy coat samples.

\begin{tabular}{|c|c|}
\hline Step scan mode & \\
\hline Tungsten wire probe & $0.5 \mathrm{~mm}$ \\
\hline Probe height (average) & $50 \mu \mathrm{m}$ \\
\hline Vibration amplitude of the probe & $25 \mu \mathrm{m}$ \\
\hline Number of lines & 96 \\
\hline Area scan (x) & $14000 \mu \mathrm{m}$ \\
\hline Area scan $(y)$ & $10500 \mu \mathrm{m}$ \\
\hline
\end{tabular}

\section{RESULTS AND DISCUSSIONS}

\section{PVB coated mild steel}

The results show line scans and area scans for a drilled defect in the PVB through to the mild steel substrate. The line scans and area scans are obtained by the Tungsten wire probe $(0.5 \mathrm{~mm}$ diameter) and has been calibrated. The two coating thicknessess used for the preliminary scans were $23 \mu \mathrm{m}$ and $112 \mu \mathrm{m}$. A number of scans for the two different thicknesses are shown, to show the ability of the SKP system to picture and detect delamination of the coating from the mild steel substrate.

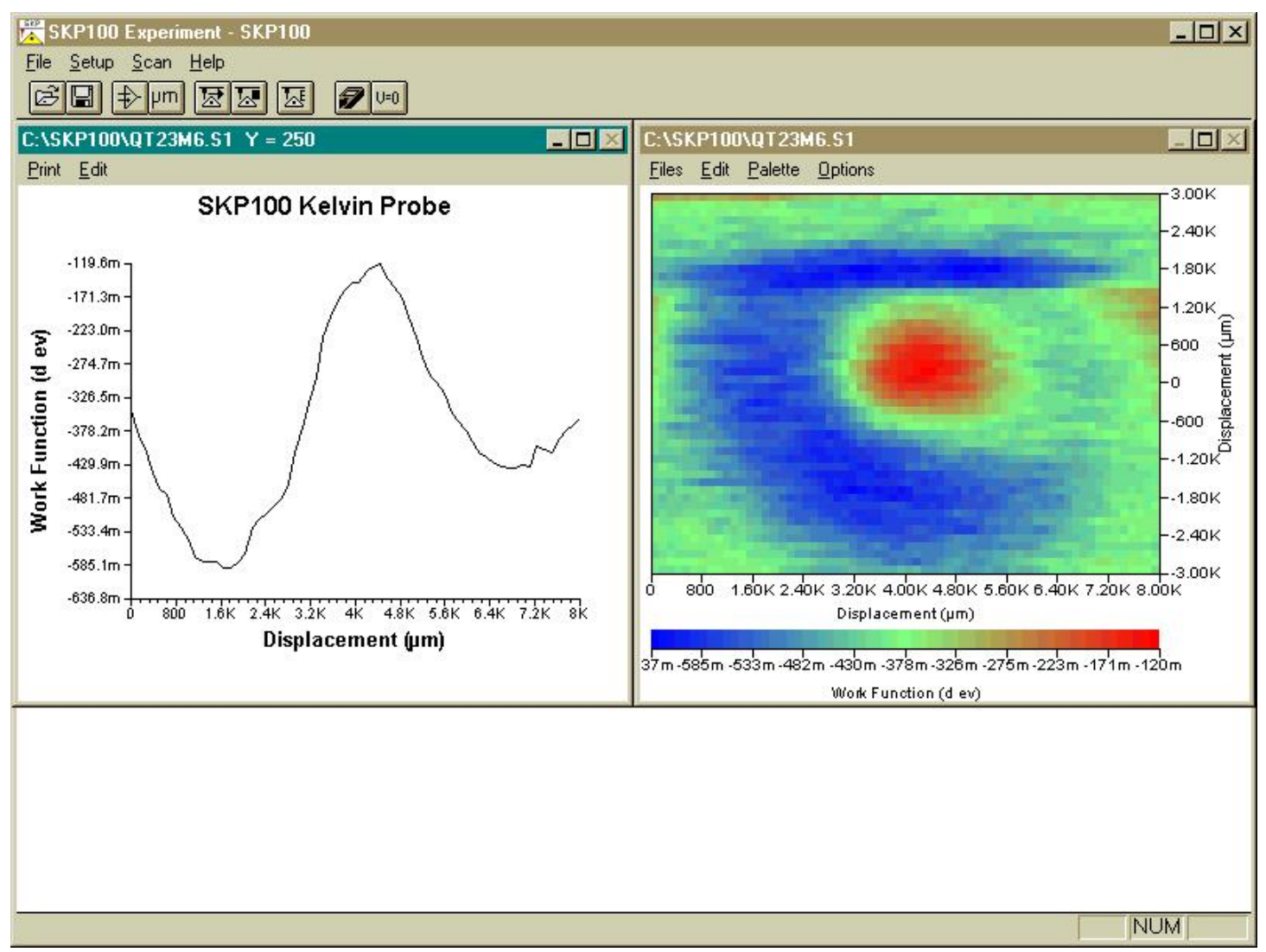

Fig.1. SKP Line scan and area scan data for a hole defect $(0.5 \mathrm{~mm}$ diameter $)$ drilled through PVB (23 $\mu$ m thickness) coating into a mild steel substrate, after 144 hrs exposure in $3.5 \% \mathrm{NaCl}$ solution. 
Figure 1 shows a line scan across the defect after $144 \mathrm{hrs}$ exposure in $3.5 \% \mathrm{NaCl}$ solution. The line scan shows three distinct regions, a region where the coating is intact and has not delaminated from the mild steel substrate and has a potential value closer to the mild steel substrate in air (-0.533 V-dark blue area observed in the area scan), the cathodic delamination is observed around the defect and this delamination front has values ranging from ( $-0.428 \mathrm{~V}$ to $-0.274 \mathrm{~V}$ - green area observed around the defect in the area scan) and the defect in the centre (peak in the line scan graph) has the highest value (-0.116 V-red area observed in the area scan) which is the local anode. The scan shows blurring around the defect and over certain areas away from the defect on either side, this may be due to some surface charge on the specimen.

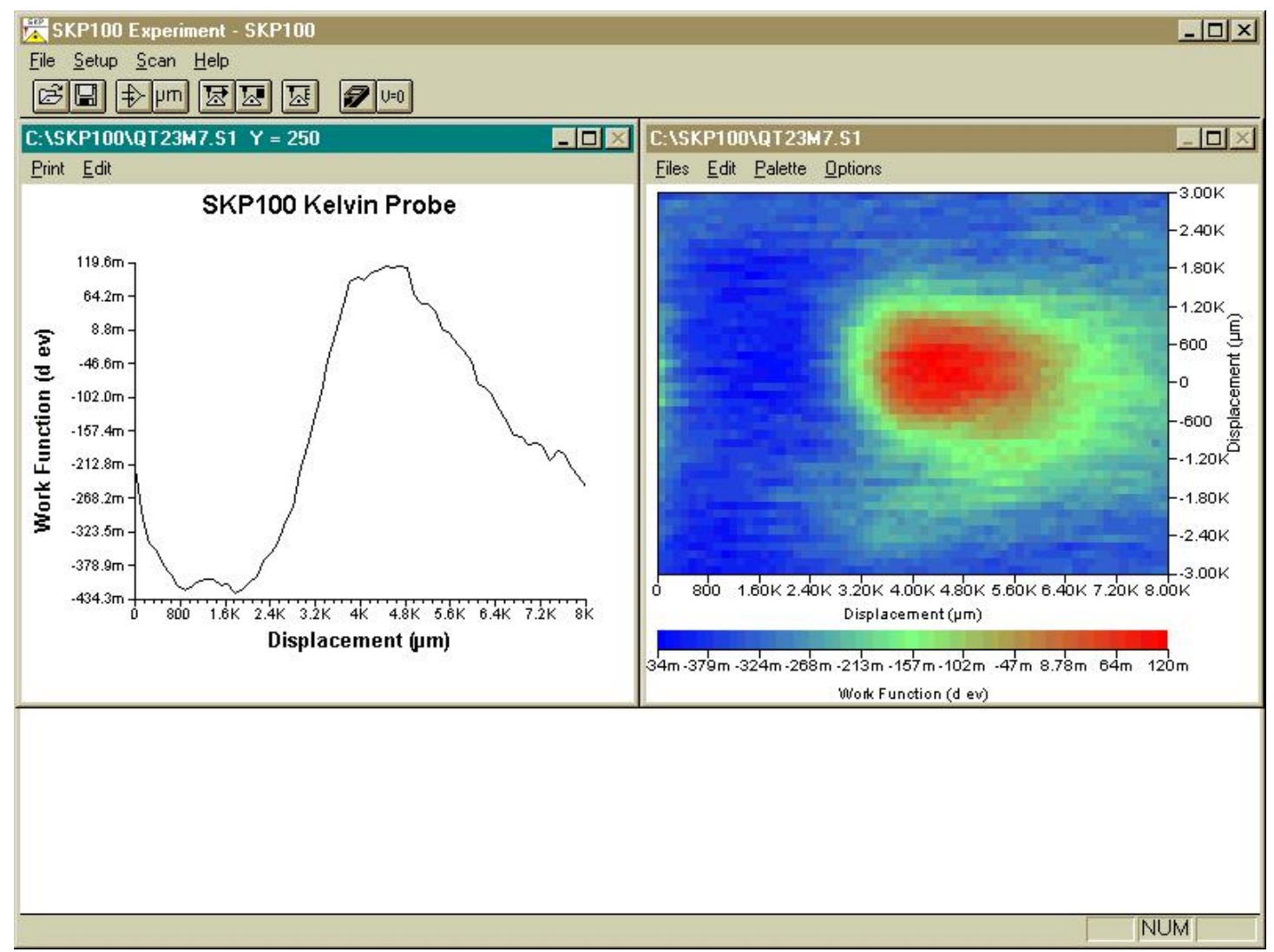

Fig.2. SKP Line scan and area scan data for a hole defect $(0.5 \mathrm{~mm}$ diameter) drilled through PVB (23 $\mu \mathrm{m}$ thickness) coating into a mild steel substrate, after $168 \mathrm{hrs}$ exposure in $3.5 \% \mathrm{NaCl}$ solution.

Figure 2 shows a line scan across the defect after $168 \mathrm{hrs}$ exposure in $3.5 \% \mathrm{NaCl}$ solution. The line scan again shows three distinct regions, a region where the coating is intact on either side of the defect, and has a potential value closer to the mild steel substrate in air (-0.434 V- dark blue area observed in the area scan), the cathodic delamination is seen around the defect and this delamination front has values from $(-0$. $\mathrm{V}$ to $0.064 \mathrm{~V}$ - green area around the defect observed 
in the area scan) and the defect in the centre has the highest value $(0.110 \mathrm{~V}$ - red area observed in the area scan) which is the local anode. In comparison the results obtained at the later exposure time, are consistent with those of the earlier exposure, the values are very similar and within experimental error. The difference between the scans is clearly evident by the increase in the red area and its full width has increased due to increase in delamination with increased exposure.

Delamination of PVB from mild steel

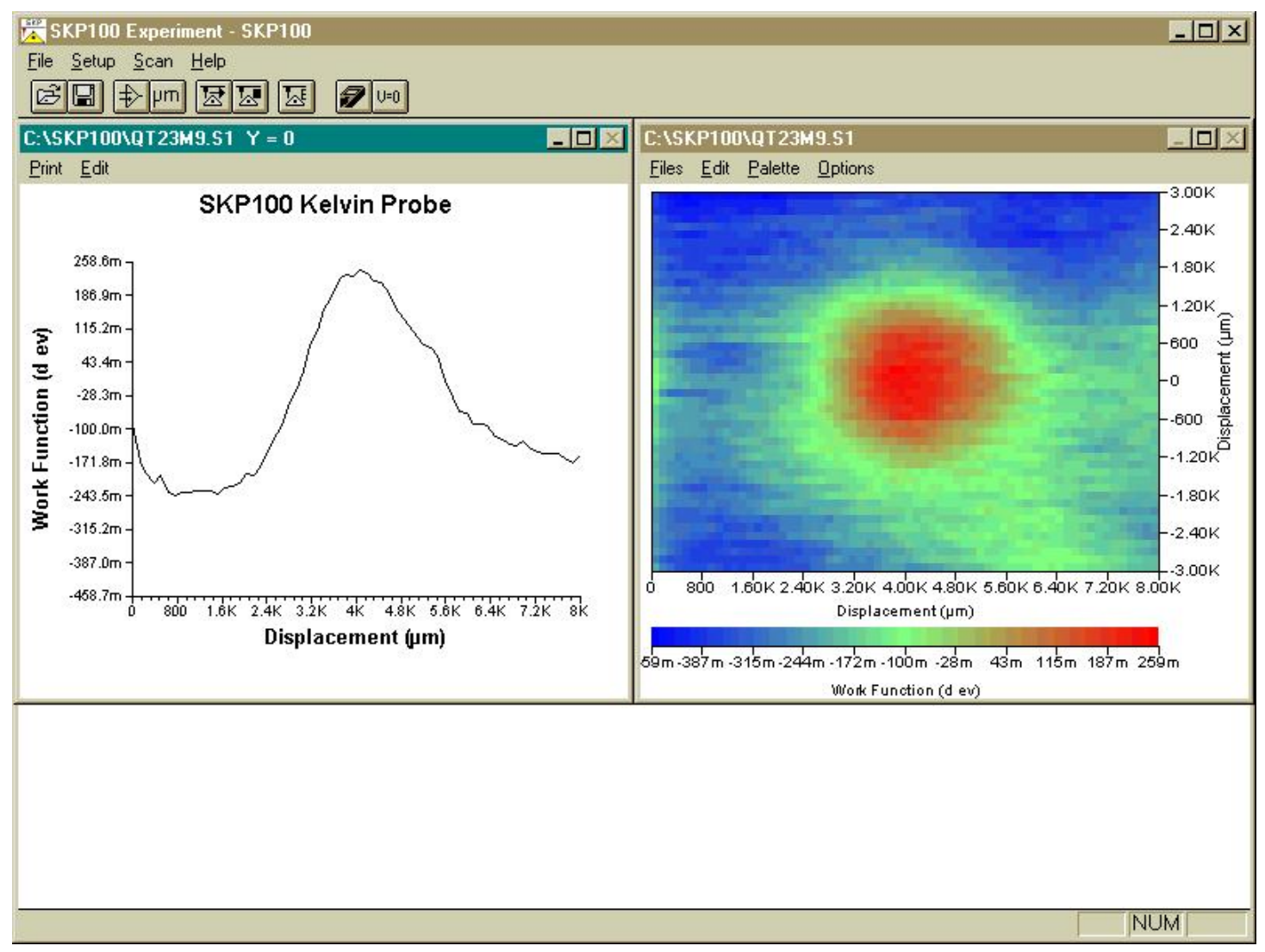

Fig.3. SKP Line scan and area scan data for a hole defect (0.5 $\mathrm{mm}$ diameter) drilled through PVB (23 $\mu \mathrm{m}$ thickness) coating into a mild steel substrate, after $216 \mathrm{hrs}$ exposure in $3.5 \% \mathrm{NaCl}$ solution.

Figure 3 shows a line scan across the defect after $216 \mathrm{hrs}$ exposure in $3.5 \% \mathrm{NaCl}$ solution and air-drying. Comparing to previous scans the results are similar, showing the different parts of the localised corrosion cell but in contrast to the other scans the width of the red area in the area scan has increased which again represents the delamination of the coating from the steel substrate. 


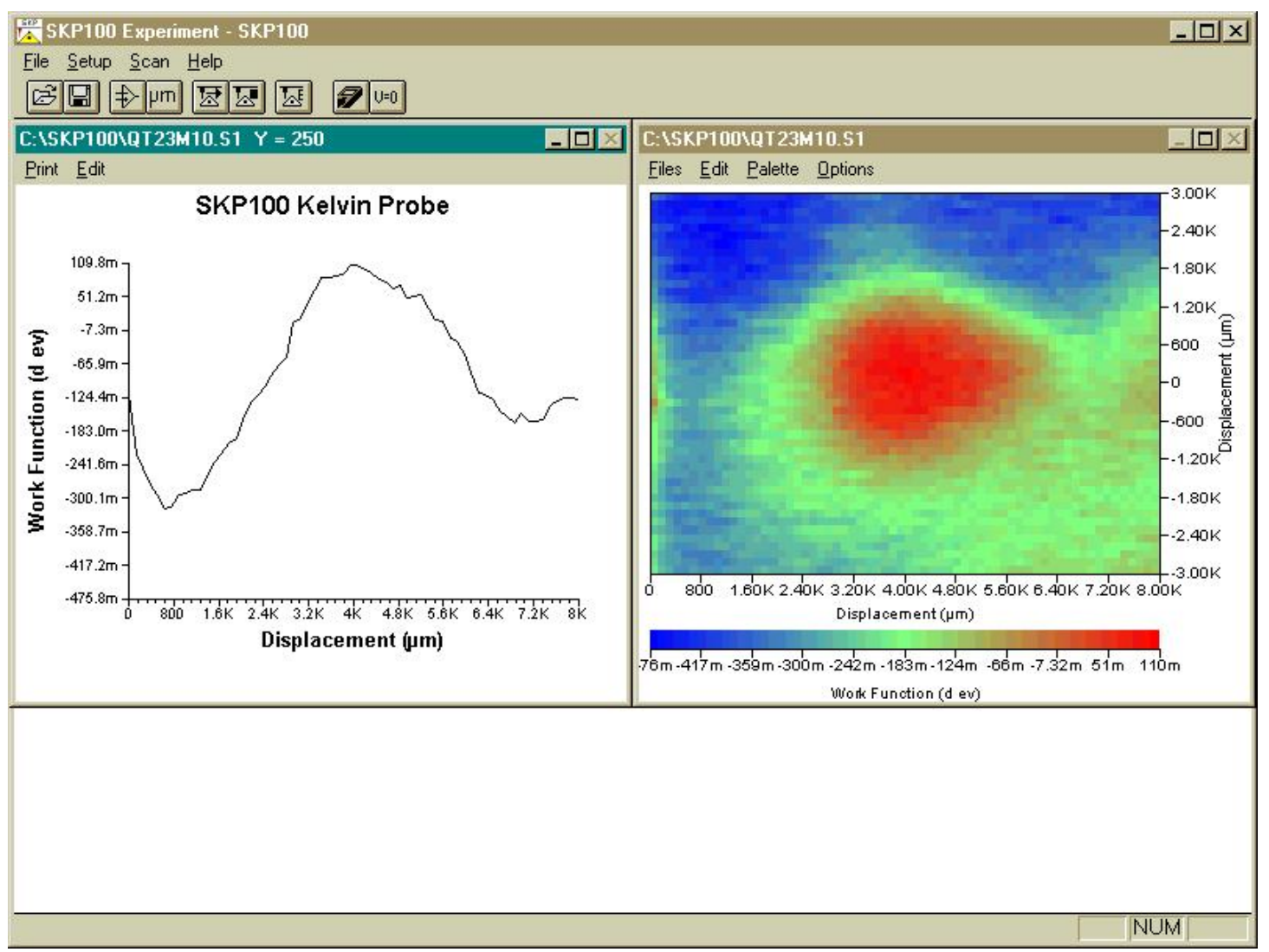

Fig.4. SKP Line scan and area scan data for a hole defect (0.5 $\mathrm{mm}$ diameter) drilled through PVB (23 $\mu \mathrm{m}$ thickness) coating into a mild steel substrate, after $240 \mathrm{hrs}$ exposure in $3.5 \% \mathrm{NaCl}$ solution. 


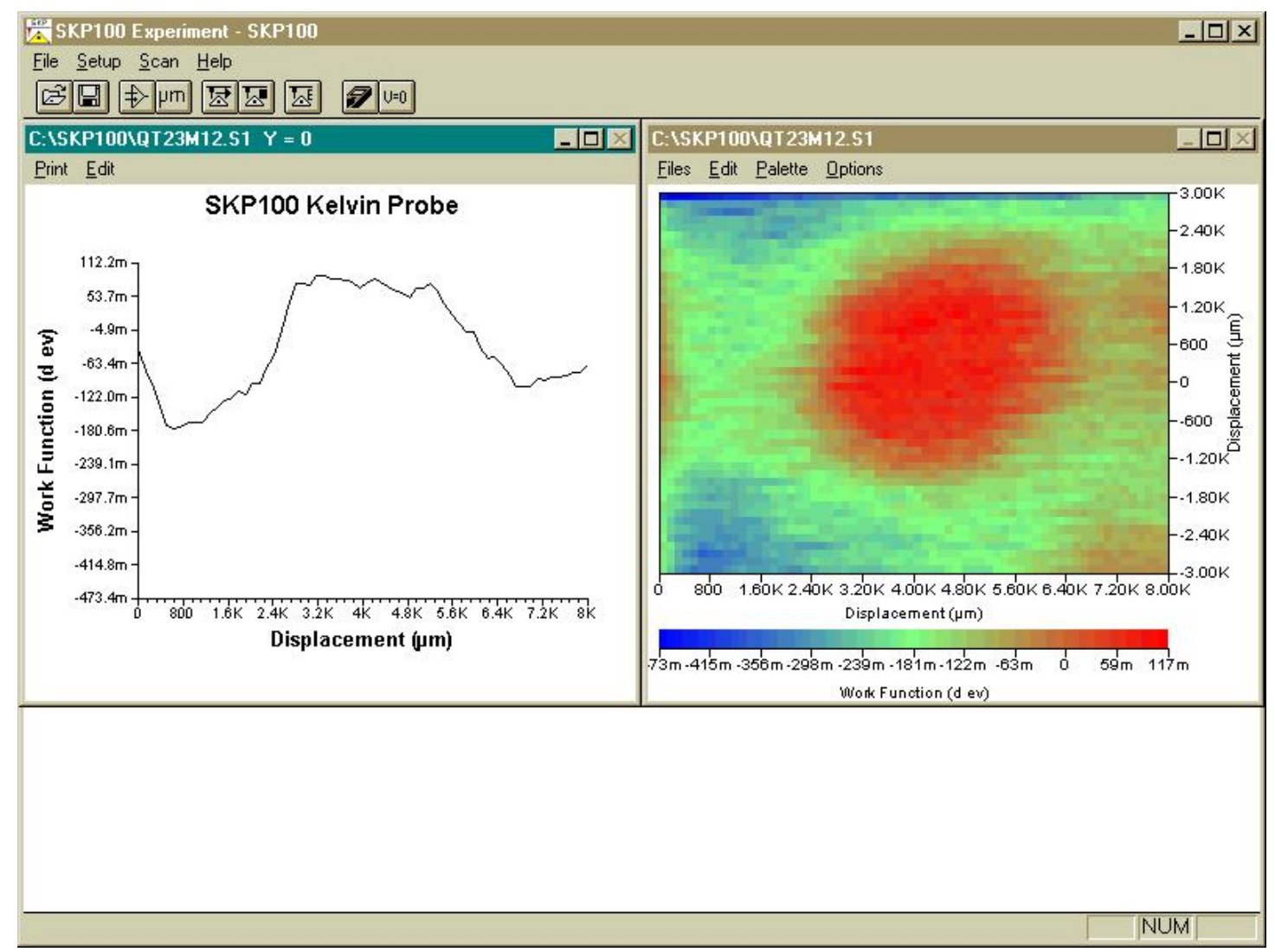

Fig.5. SKP Line scan and area scan data for a hole defect $(0.5 \mathrm{~mm}$ diameter) drilled through PVB (23 $\mu \mathrm{m}$ thickness) coating into a mild steel substrate, after $288 \mathrm{hrs}$ exposure in $3.5 \% \mathrm{NaCl}$ solution.

Figure 4 and Figure 5 shows line scans across the defect after 240 hrs and 288 hrs exposure in $3.5 \% \mathrm{NaCl}$ solution respectively. The main features of these scans are same as previous scans showing the different areas of the defected and intact areas on the specimen. The feature of most interest again is the red area as its full width has increased with increased exposure to the corrosive solution. The potential values for the different areas of the specimen are in line with those measured in previous scans, showing the reproducibility of the instrument. 


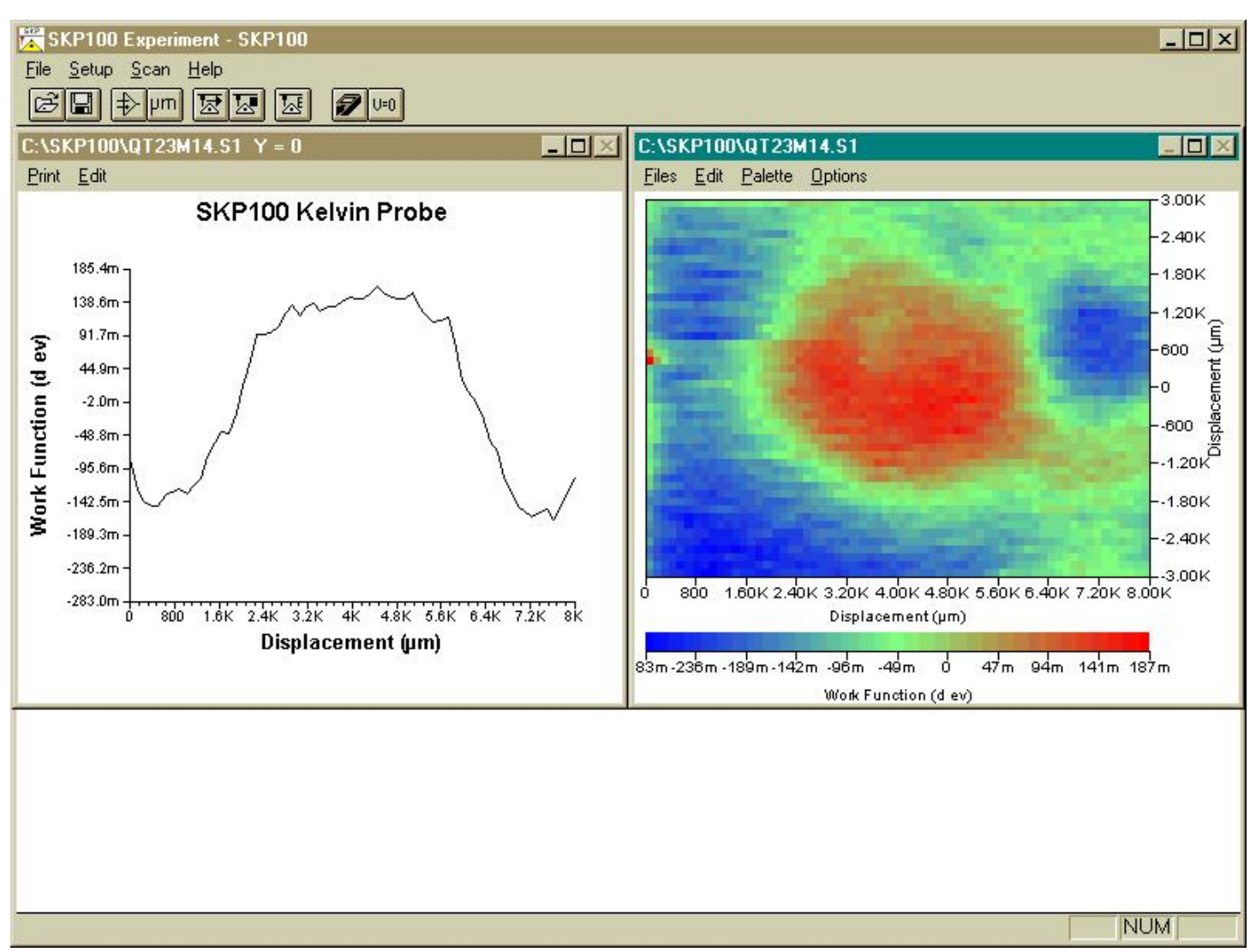

Fig.6. SKP Line scan and area scan data for a hole defect $(0.5 \mathrm{~mm}$ diameter $)$ drilled through PVB (23 $\mu$ m thickness) coating into a mild steel substrate, after $336 \mathrm{hrs}$ exposure in $3.5 \% \mathrm{NaCl}$ solution.

A final scan (Figure 6), shows the longest exposure to the solution and the greatest delamination (full width of red section in the area scan). In contrast to the earliest exposure time, there is a considerable change in the width of the red section in the area scan. The potential values are overall slightly more negative for the earliest exposure time scans, then for the final exposure scans. There might be several reasons for this; due to longer exposure there would be more of a shift to positive potential. These would occur due to the penetration of anions between the coating and the substrate. Also, with the sensitivity limit of the SKP system maybe it is unable to resolve fully the anodic and cathodic parts of the localised corrosion cell. 


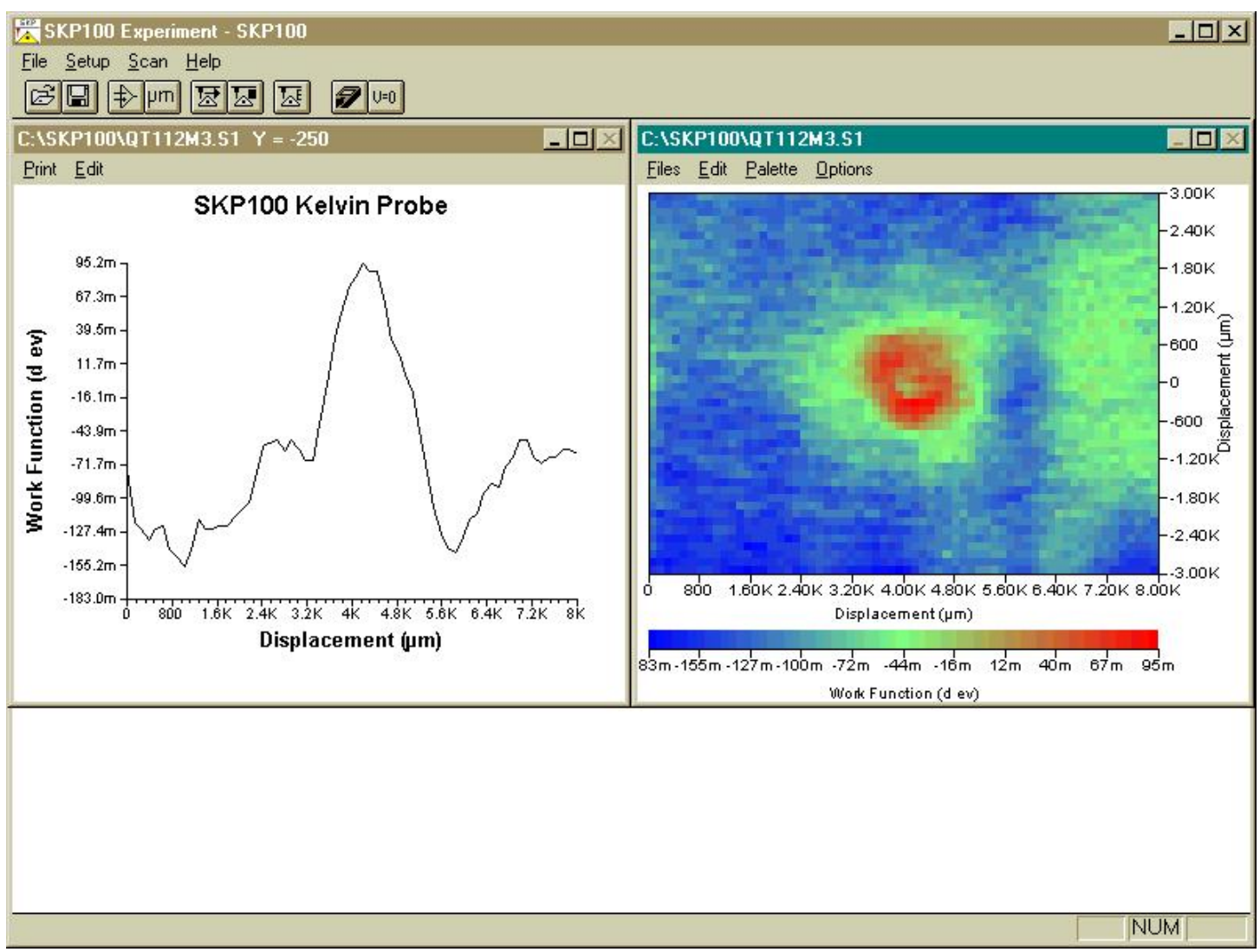

Fig.7. SKP Line scan and area scan data for a hole defect ( $0.5 \mathrm{~mm}$ diameter) drilled through PVB (112 $\mu \mathrm{m}$ thickness) coating into a mild steel substrate, after $72 \mathrm{hrs}$ exposure in $3.5 \% \mathrm{NaCl}$ solution.

Figure 7 shows a line scan and an area scan for a hole defect after $72 \mathrm{hrs}$ exposure in $3.5 \%$ $\mathrm{NaCl}$ solution. The line scan shows three distinct regions, a region where the coating is intact and has not delaminated from the mild steel substrate and would expect a potential value closer to the mild steel substrate in air $(-0.142 \mathrm{~V}$ - dark blue area in the area scan, on either side of the defect), cathodic delamination is seen around the defect and this delamination front has values ranging from (-0.099 $\mathrm{V}$ to $0.039 \mathrm{~V}$ - green area around the defect in the area scan) and the defect in the centre has the highest value (0.095 V-red area in the area scan) which is the local anode. The line scan and the area scan highlight clearly the three distinct regions of the specimen. As, in the case of the $23 \mu \mathrm{m}$ PVB coating, looking to observe the delamination of the coating from the substrate. In contrast to the $23 \mu \mathrm{m}$, having a thicker coat of polymer, more defined edges are seen around the defect, which is observed by the system. The defect having more defined areas, can give more accurate spread of delamination around the defect. The potential measured for the $112 \mu \mathrm{m}$ even at its lowest exposure time is slightly more positive. 


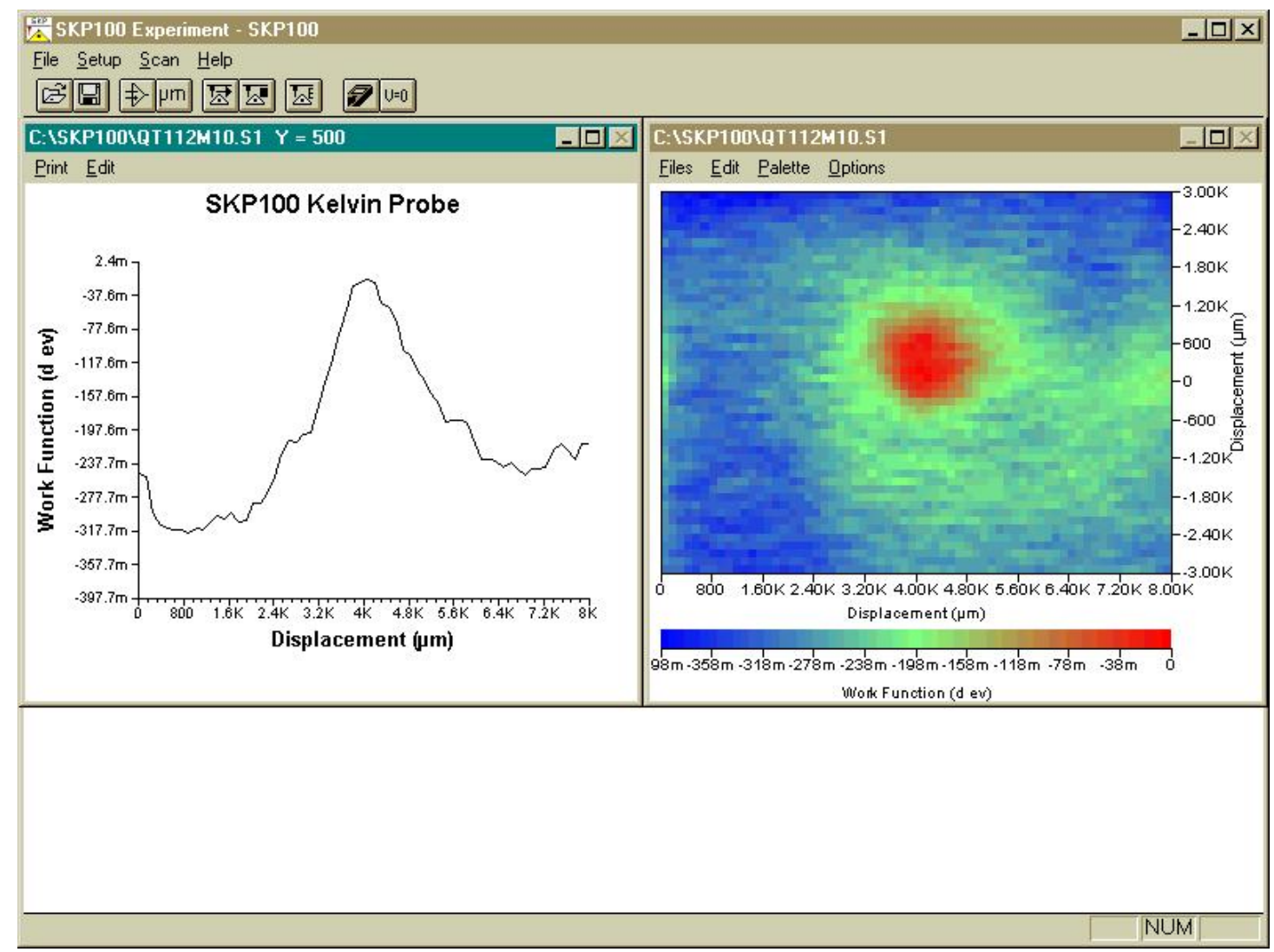

Fig.8. SKP Line scan and area scan data for a hole defect ( $0.5 \mathrm{~mm}$ diameter) drilled through PVB (112 $\mu \mathrm{m}$ thickness) coating into a mild steel substrate, after $240 \mathrm{hrs}$ exposure in $3.5 \%$ $\mathrm{NaCl}$ solution.

The line scan and area scan shows the defect after $240 \mathrm{hrs}$ exposure in $3.5 \% \mathrm{NaCl}$ solution. The line scan shows three distinct regions, a region where the coating is intact and has not delaminated from the mild steel substrate and has a potential value closer to the mild steel substrate in air (-0.317 V- dark blue region in the area scan around the hole defect), cathodic delamination is seen around the defect and this delamination front has values ranging from ($0.237 \mathrm{~V}$ to $-0.077 \mathrm{~V}$-green area just surrounding the defect) and the defect in the centre has the highest value again (-0.037 V-red area in the centre of the area scan) which is the local anode. The line and area scans clearly show the three distinct regions of the localised corrosion cell. Again, looking at the spread of delamination (increase in full width of the red area in the centre of the area scan). The full width has increased with increased exposure time. 


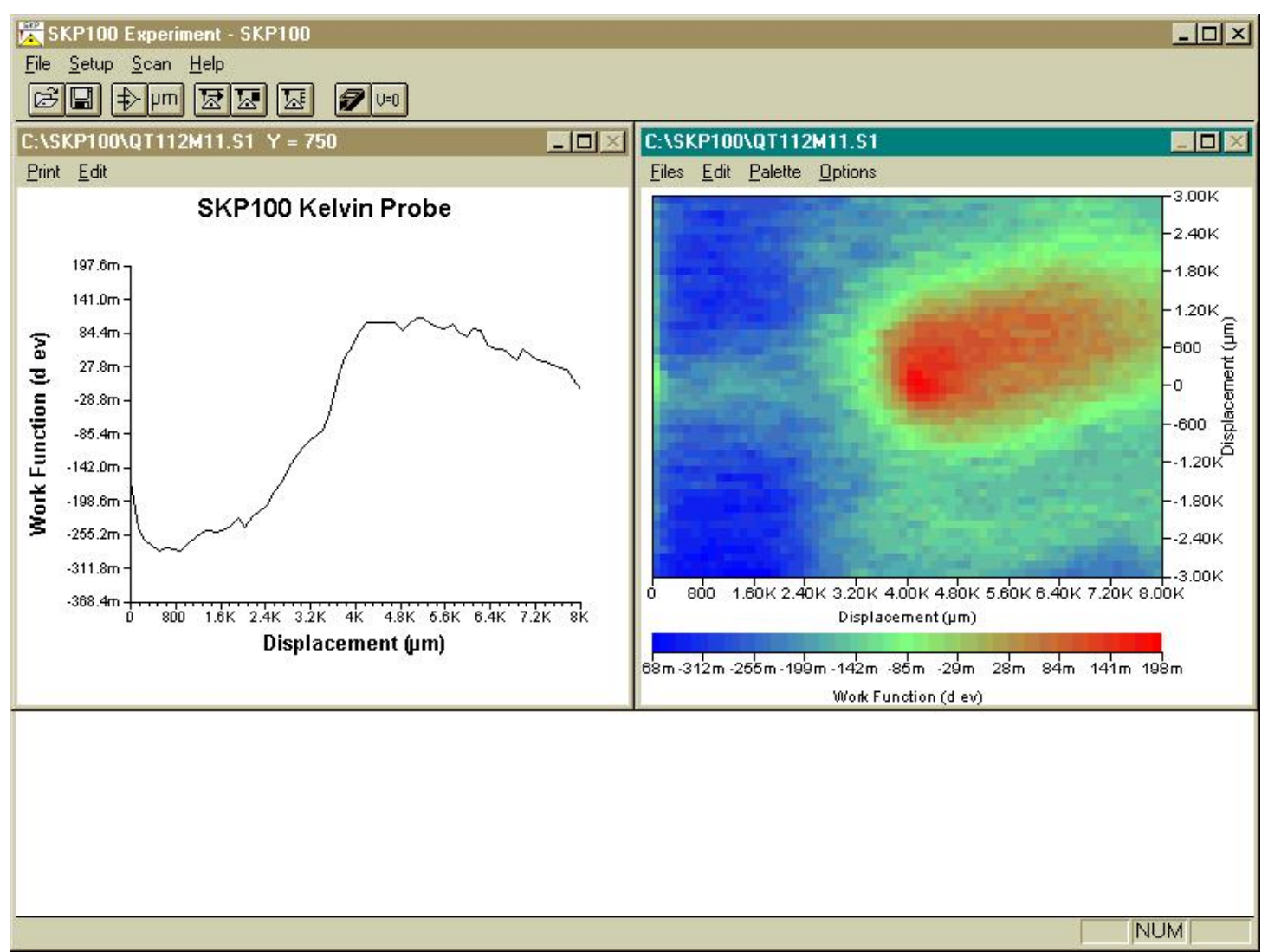

Fig.9. SKP Line scan and area scan data for a hole defect ( $0.5 \mathrm{~mm}$ diameter) drilled through PVB (112 $\mu \mathrm{m}$ thickness) coating into a mild steel substrate, after $264 \mathrm{hrs}$ exposure in $3.5 \%$ $\mathrm{NaCl}$ solution. 


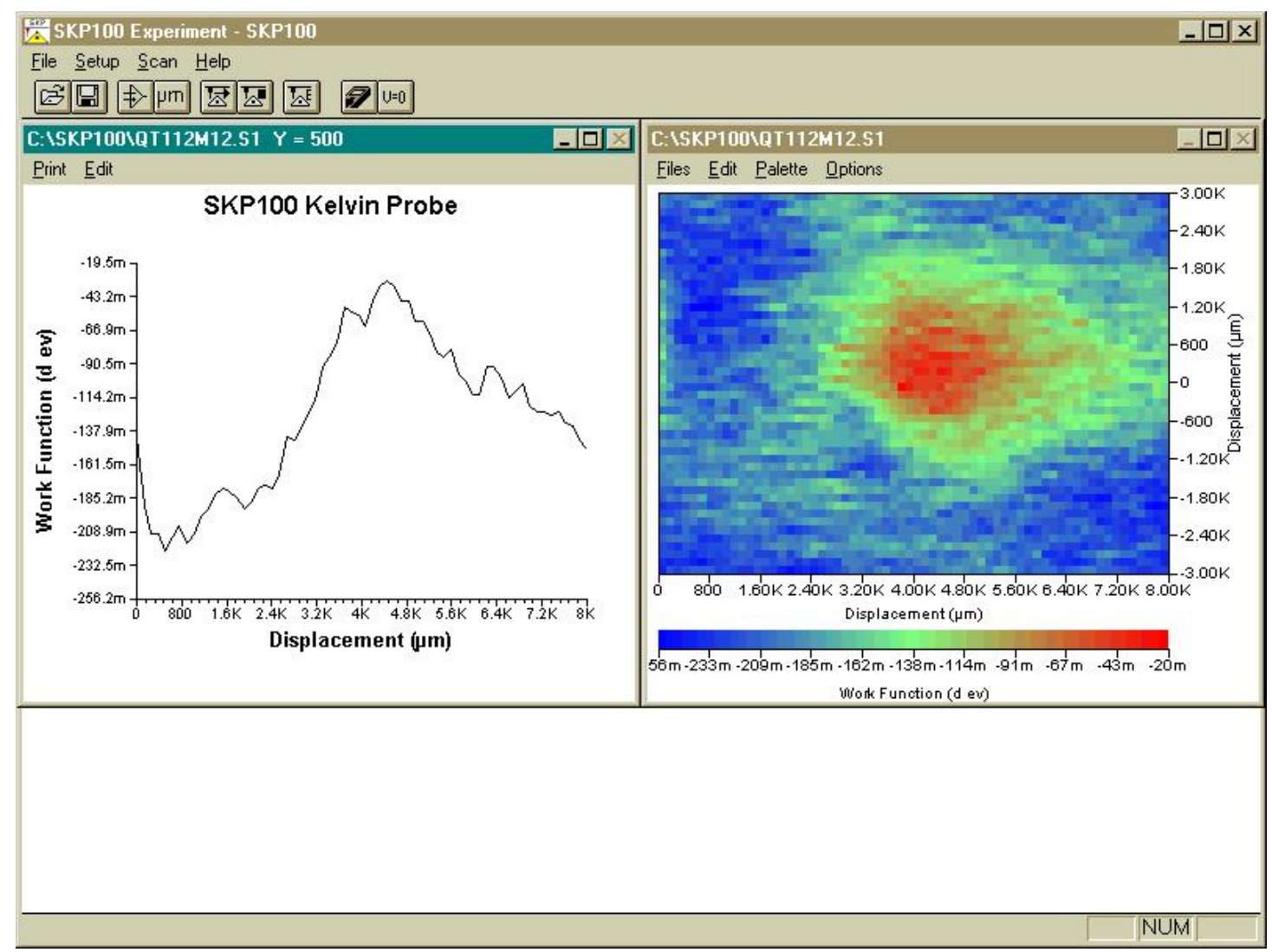

Fig.10. SKP Line scan and area scan data for a hole defect $(0.5 \mathrm{~mm}$ diameter $)$ drilled through PVB (112 $\mu \mathrm{m}$ thickness) coating into a mild steel substrate, after $288 \mathrm{hrs}$ exposure in $3.5 \%$ $\mathrm{NaCl}$ solution.

Figure 9 and Figure 10 show line scan and area scans for the introduced defect after $264 \mathrm{hrs}$ and $288 \mathrm{hrs}$ exposure in $3.5 \% \mathrm{NaCl}$ solution respectively. The line scan and area scans show three distinct regions on the specimen as for previous exposure times and also for $23 \mu \mathrm{m}$. The values are very similar for the different exposure time scans, as same sample is used. The reproducibility of the instrument is also good as same potentials are observed for different exposure times. The full width of the red area has increased with increased exposure time. 


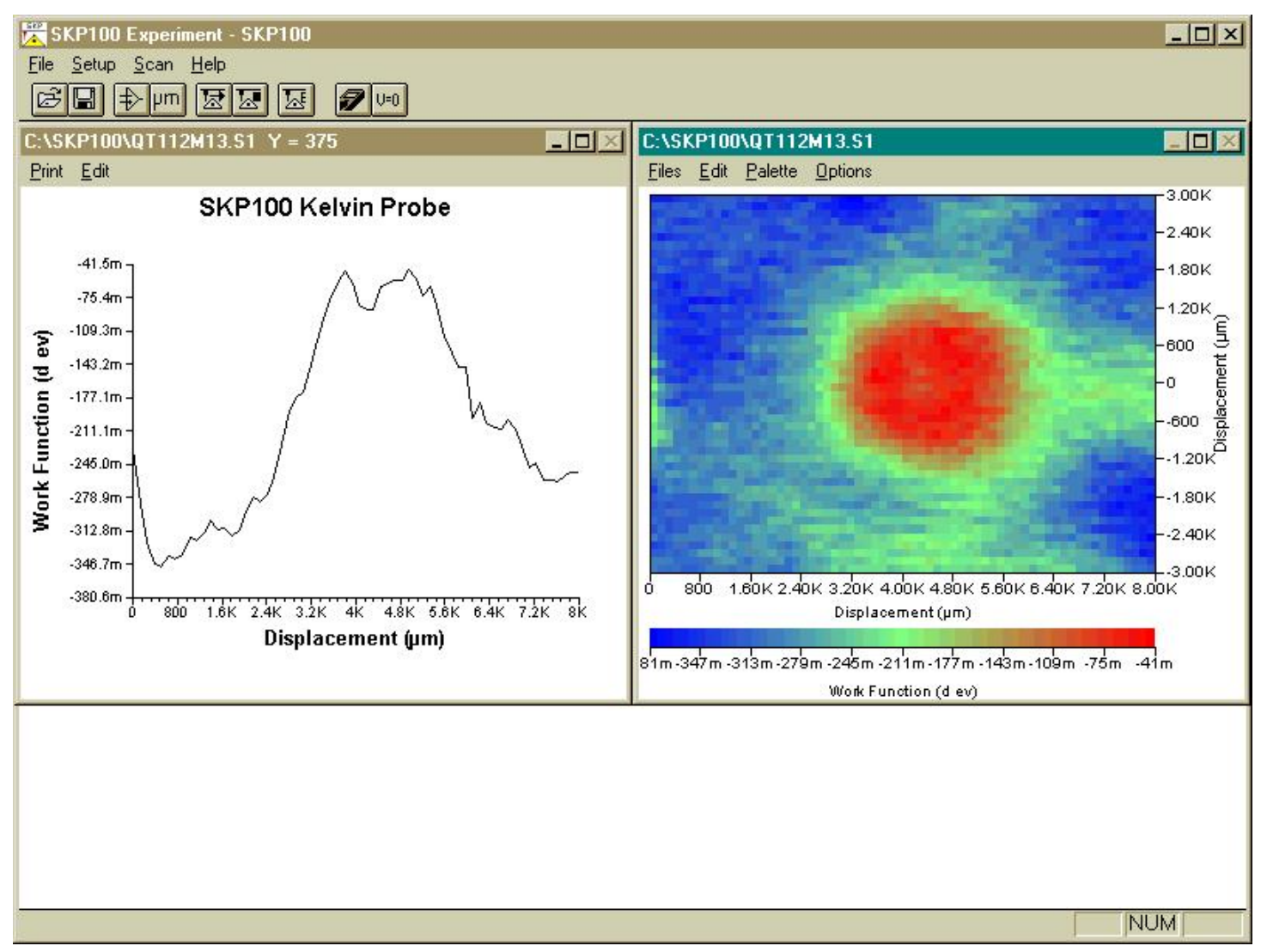

Fig.11. SKP Line scan and area scan data for a hole defect $(0.5 \mathrm{~mm}$ diameter $)$ drilled through PVB $(112 \mu \mathrm{m}$ thickness) coating into a mild steel substrate, after $312 \mathrm{hrs}$ exposure in $3.5 \%$ $\mathrm{NaCl}$ solution and air-drying.

Figure 11 The line scan and area scan for the greatest exposure time shows the biggest spread in delamination (greatest increase in the full width of the red area in the area scan). 


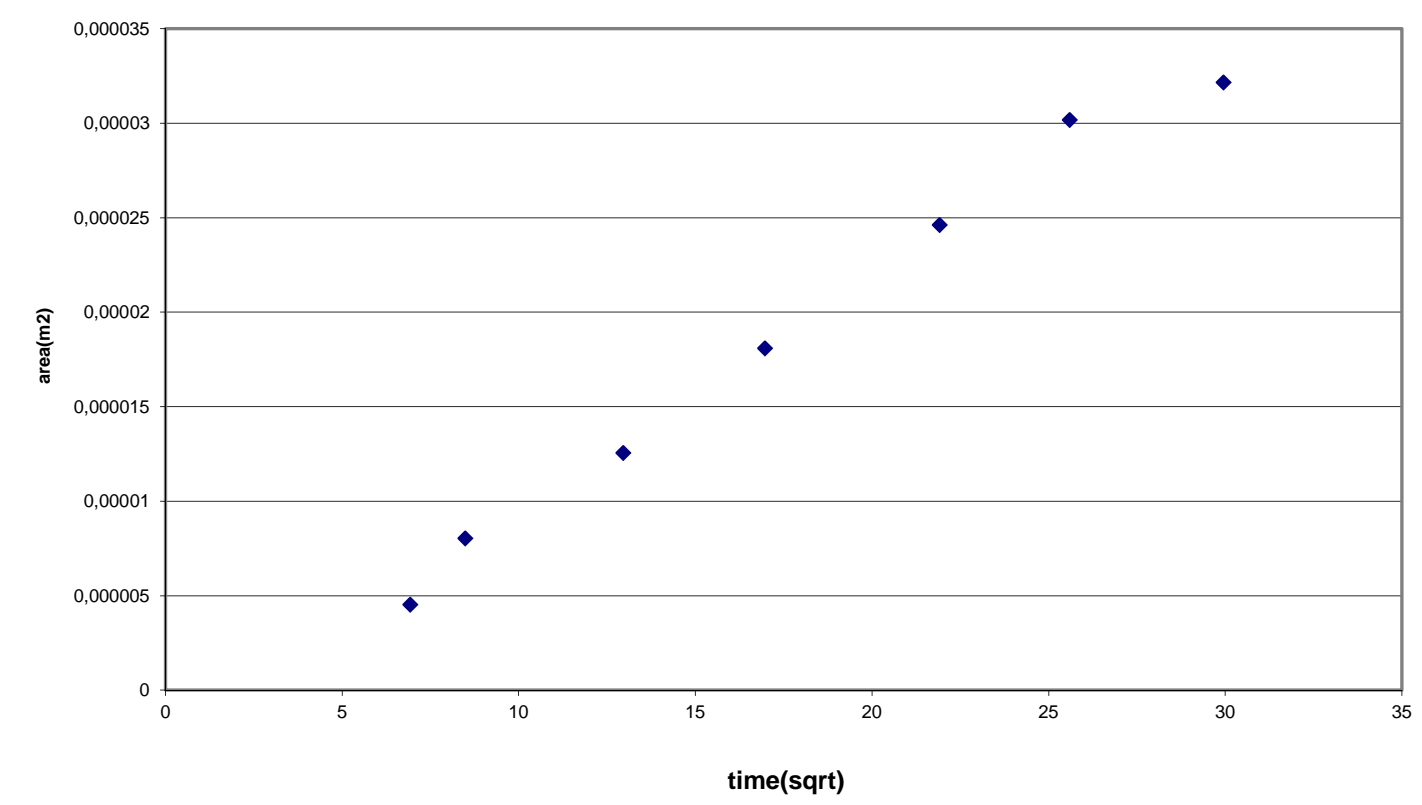

Fig.12. Plot showing the increase in delamination over exposure time with PVB $(23 \mu \mathrm{m}$ thickness) on mild steel substrate with a hole defect $(0.5 \mathrm{~mm}$ diameter) through the coating into the substrate.

The delamination is determined by measuring the full width of the red area from the area scans at different exposure times. This full width is used to obtain the area of the defect and this is plotted against square root of time. The plot highlights a number of points. It clearly shows that the full width of the red area in the area scan has spread, therefore, an increase in the delamination area of the coating from the substrate. The initiation period preceding the onset of corrosion-driven coating delamination is similar to 'delay times and probably corresponds to the time taken for sufficient electrolyte to diffuse into or beneath, the epoxy coating to support under film electrochemical activity. The instrument detects this and the relationship is also approximately proportional to the square root of time implying a diffusion process. 


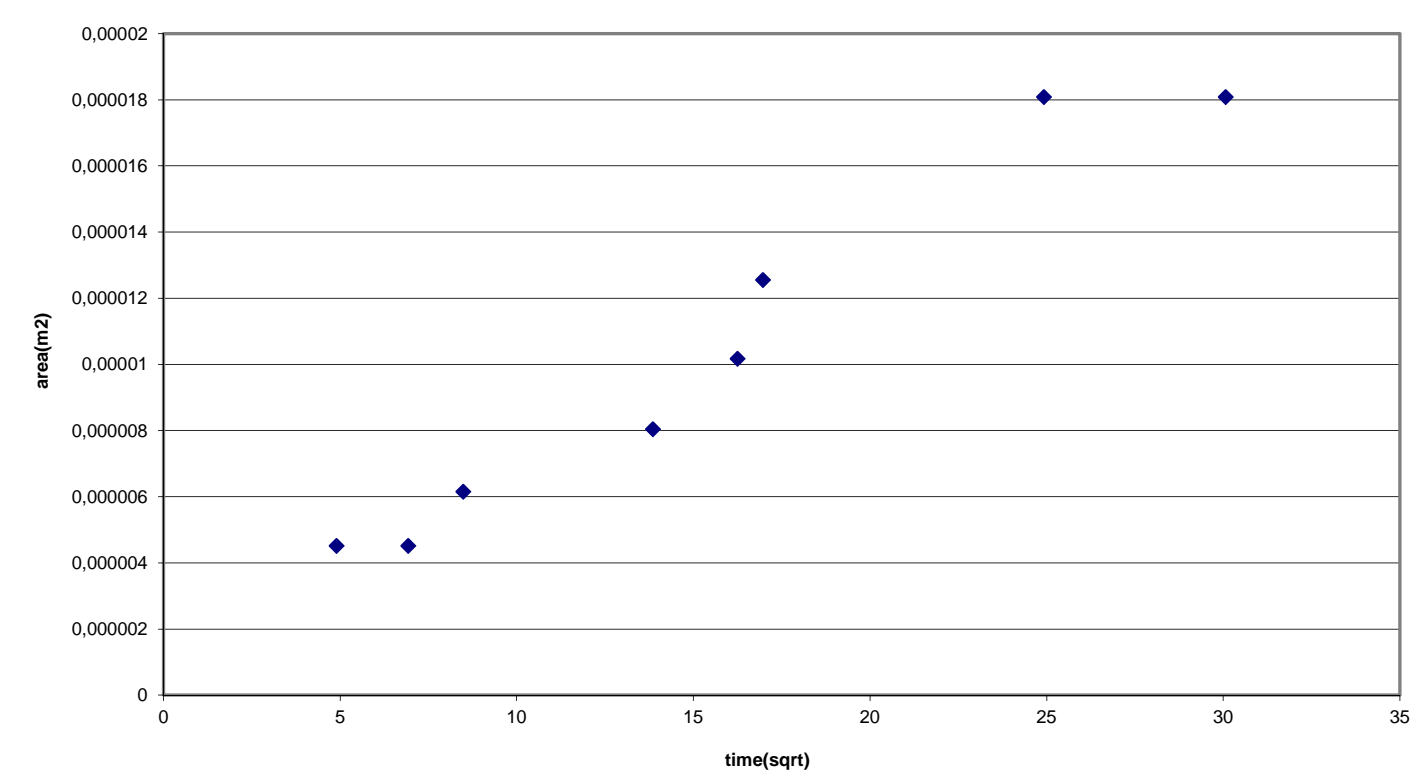

Fig.13. Plot showing the increase in delamination over exposure time with PVB $(112 \mu \mathrm{m}$ thickness $)$ on mild steel substrate with a hole defect $(0.5 \mathrm{~mm}$ diameter $)$ through the coating into the substrate.

The delamination is again measured as for the $23 \mu \mathrm{m}$ case, the full width of the red area in the SKP area scans is noted for the different exposure times, and the full area of the defect is obtained and plotted against the square root of exposure time. Therefore the plot shows the delamination (increase in full width of the red area in the area scans) of the coating from the substrate. A 'delay time' is again observed as in the case of $23 \mu \mathrm{m}$ delamination plot. The plot shows again a relationship, which is approximately proportional to the square root of time implying diffusion process. The plot at certain points deviates from unity due to surface charge, which was evident from the SKP area scans. This electrostatic charge was mostly removed by leaving the sample in air.

The SKP results are represented as line scans for the different defects on various thicknesses of PVB on a mild steel substrate and galvanised steel substrate. PVB is used as a model coating because it is unlikely to develop significant fixed charge density, as it does not contain polar groups. Furthermore, the concentration of the aqueous $\mathrm{NaCl}$ electrolyte is high. Using this coating shows the ability of the instrument to measure and picture the delamination process. 


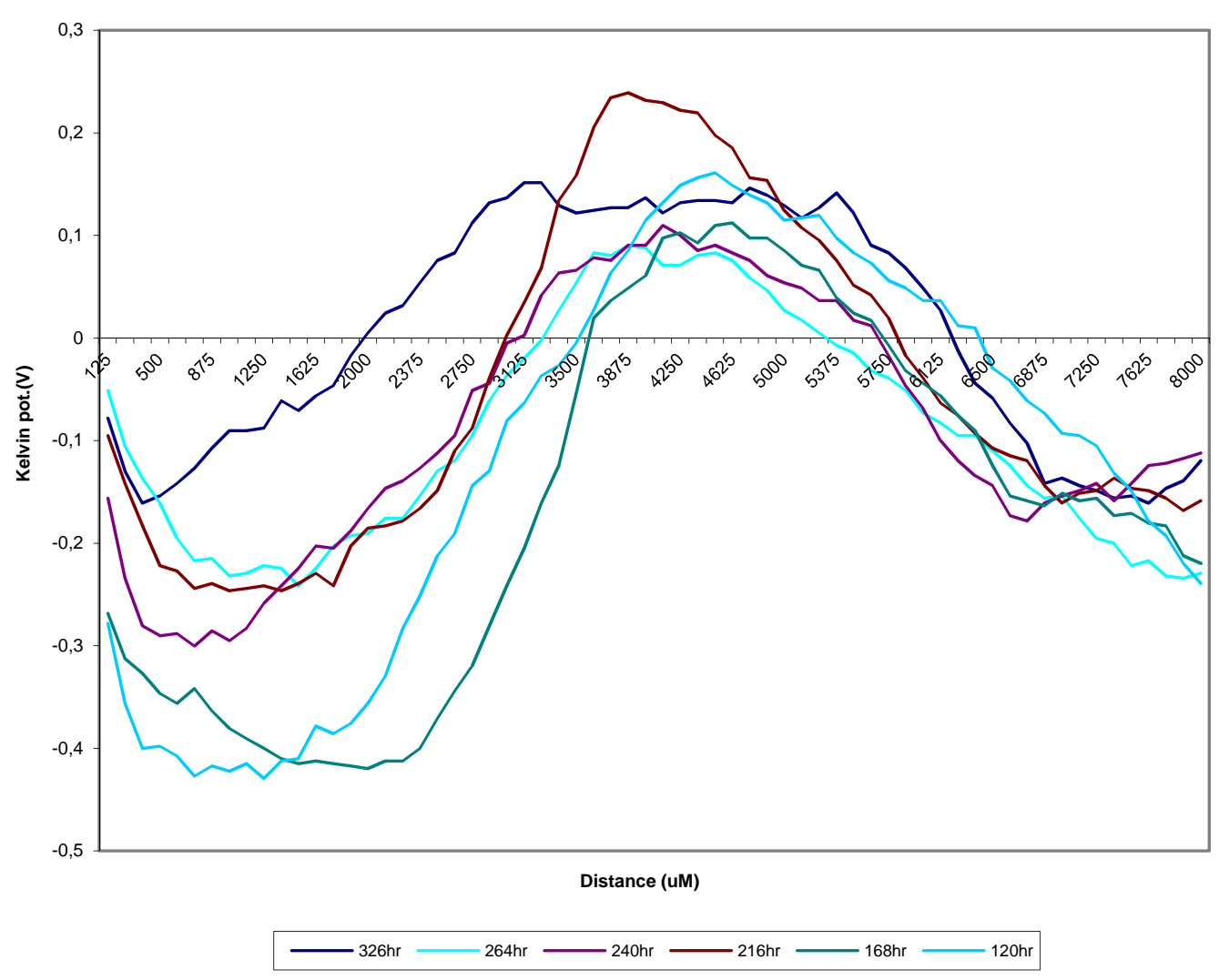

Fig.14. SKP line scan data for different exposure times with Poly Vinyl Butyral $(23 \mu \mathrm{m}$ thickness) on mild steel substrate with a hole defect ( $0.5 \mathrm{~mm}$ diameter) through the coating into the substrate.

The vibrating probe is placed at the centre of the defect and the full defect is scanned and also some intact area around the defect. In step area scan mode, at the centre of the defect a peak is observed (Figure 14), as the probe scans away from the defect on either side a gradual drop is observed and then it levels to show the intact coating furthest from the defect. The plot shows that for different exposure times the lines across the hole defect increase in width, which is comparable to the delamination of the PVB coating from the substrate. 


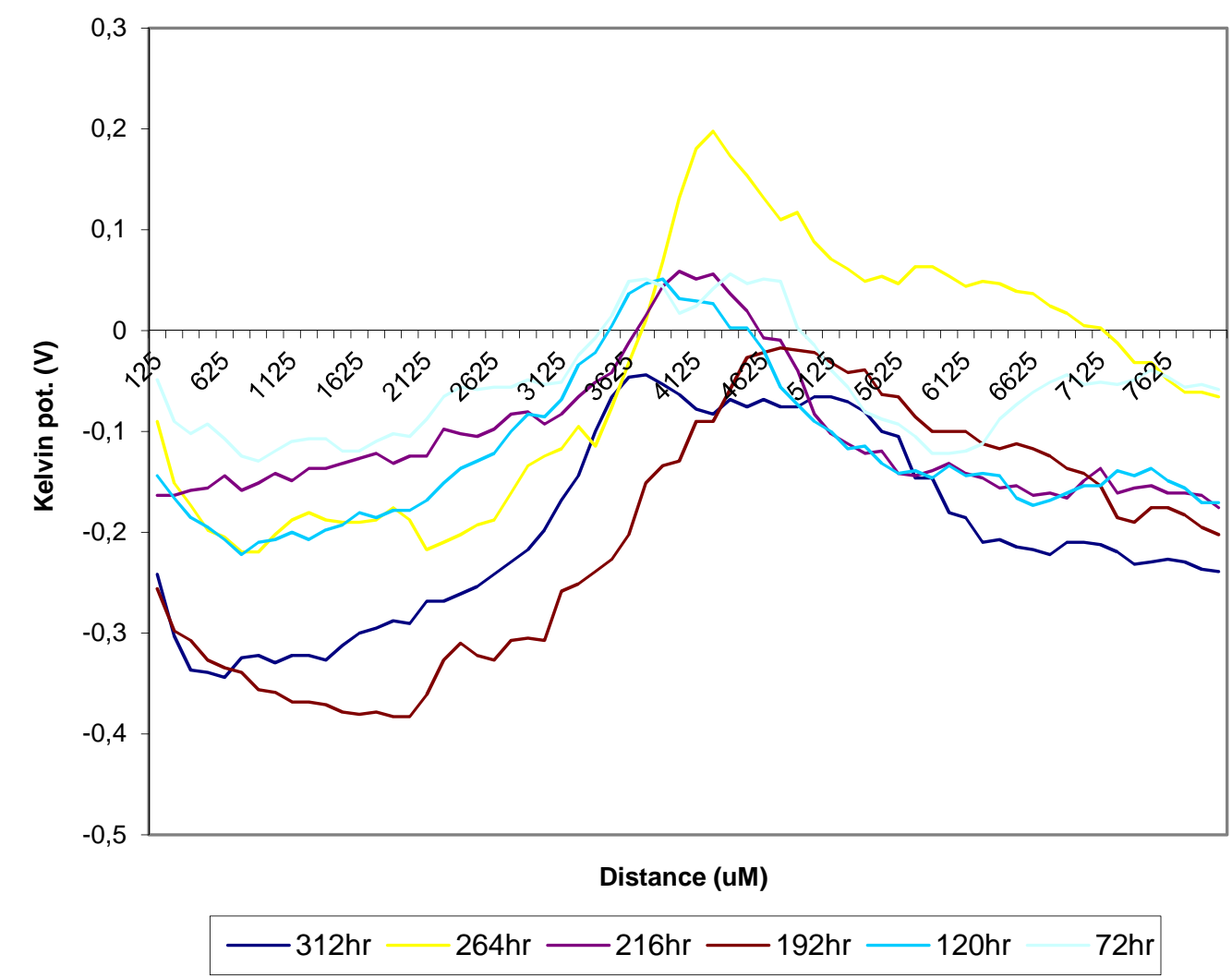

Fig.15. SKP line scan data for different exposure times with PVB (112 $\mu \mathrm{m}$ thickness) on mild steel substrate with a hole defect $(0.5 \mathrm{~mm}$ diameter) through the coating into the substrate.

Observing a thicker coat of PVB on mild steel, the instrument again shows a central peak for the hole defect and then a gradual decrease, then becoming steady furthest from the defect. The reproducibility of the instrument can be clearly seen, as the values are very similar for the two different thickness of PVB coating. The instrument is also capable of detecting the delamination processes with a thicker coating of PVB on the mild steel substrate. 


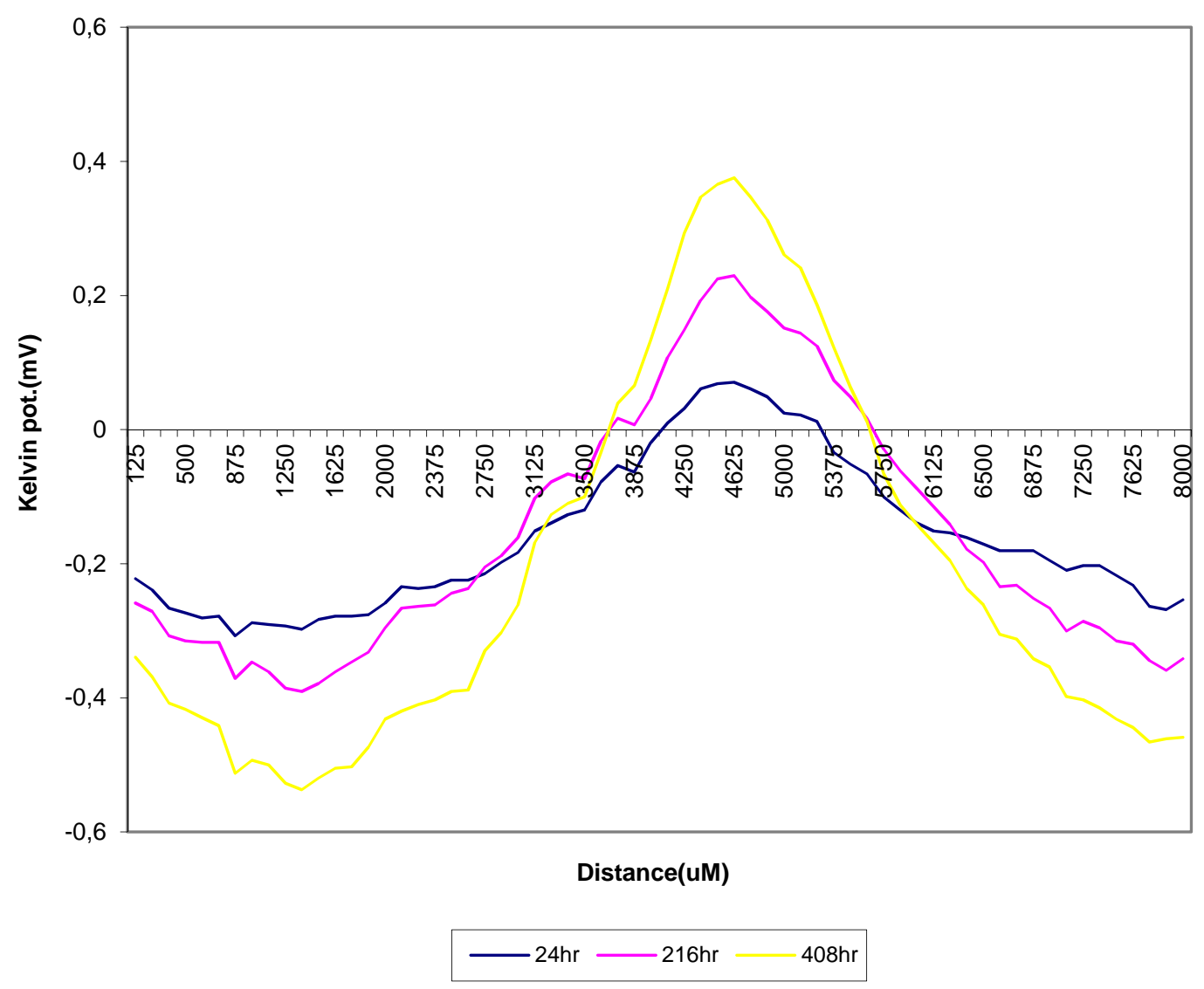

Fig.16. SKP line scan data for different exposure times with PVB ( $45 \mu \mathrm{m}$ thickness) on mild steel substrate with a hole defect $(0.5 \mathrm{~mm}$ diameter) through the coating into the substrate. 


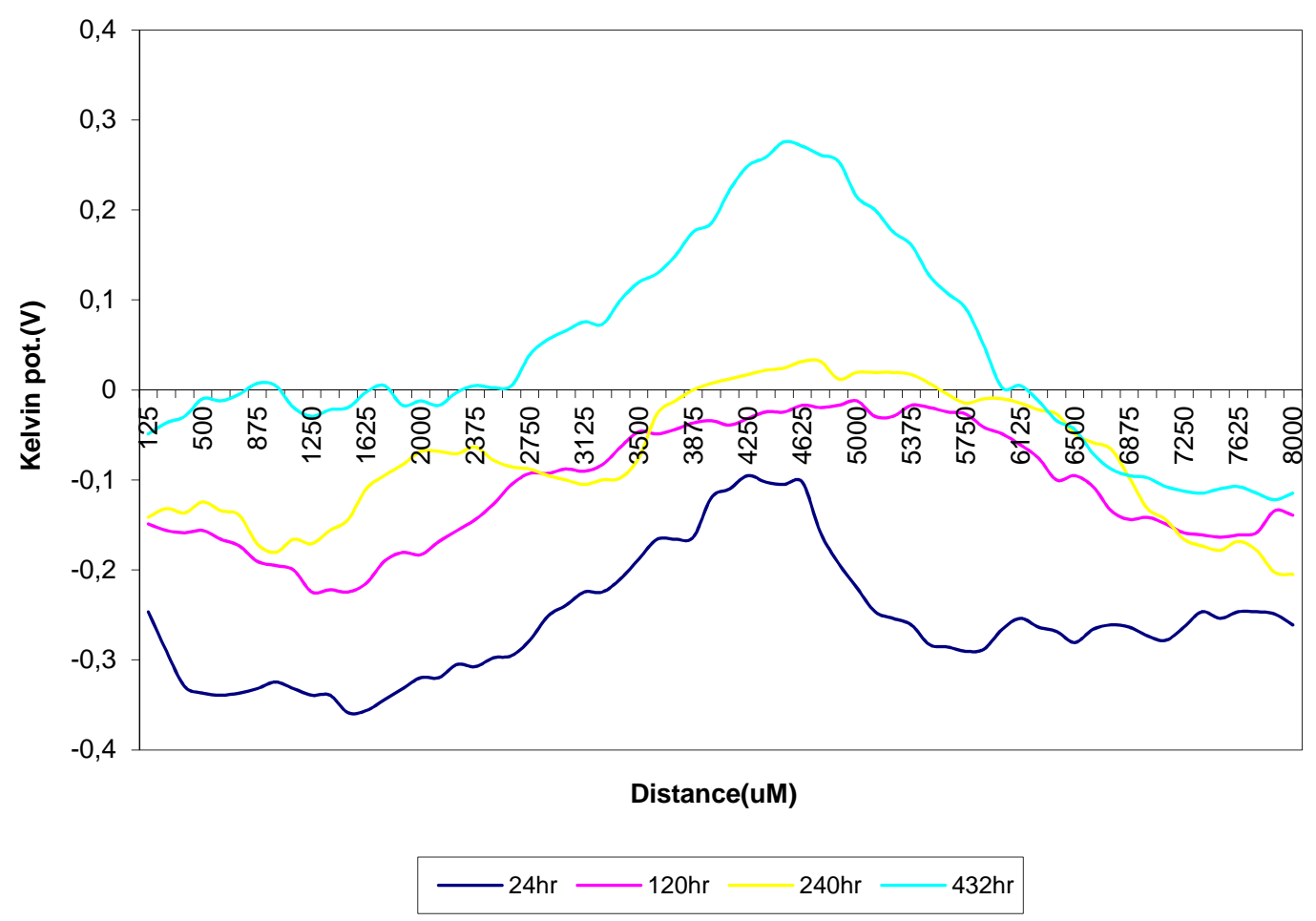

Fig.17. SKP line scan data for different exposure times with PVB (55 $\mu \mathrm{m}$ thickness) on mild steel substrate with a hole defect $(0.5 \mathrm{~mm}$ diameter) through the coating into the substrate.

The consistency of results can be further confirmed as comparison of two different thickness of PVB on the mild steel substrate. The line scan in comparison with previous scans shows the delamination. Comparing the two thicknesses the potential values are similar and the rate of delamination is also similar. 


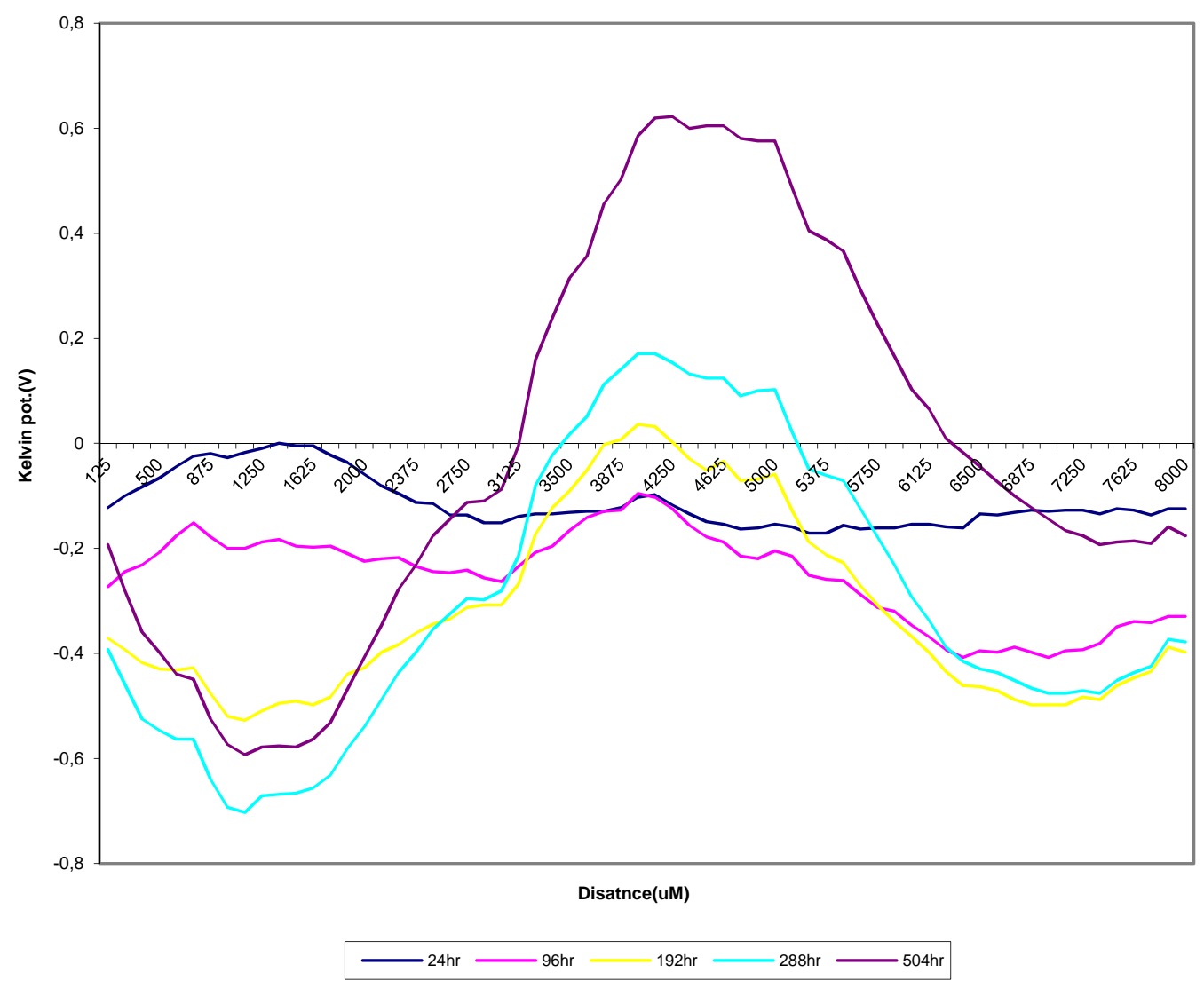

Fig.18. SKP line scan data for different exposure times with PVB (35 $\mu \mathrm{m}$ thickness) on mild steel substrate with a scratch defect through the coating into the substrate. 


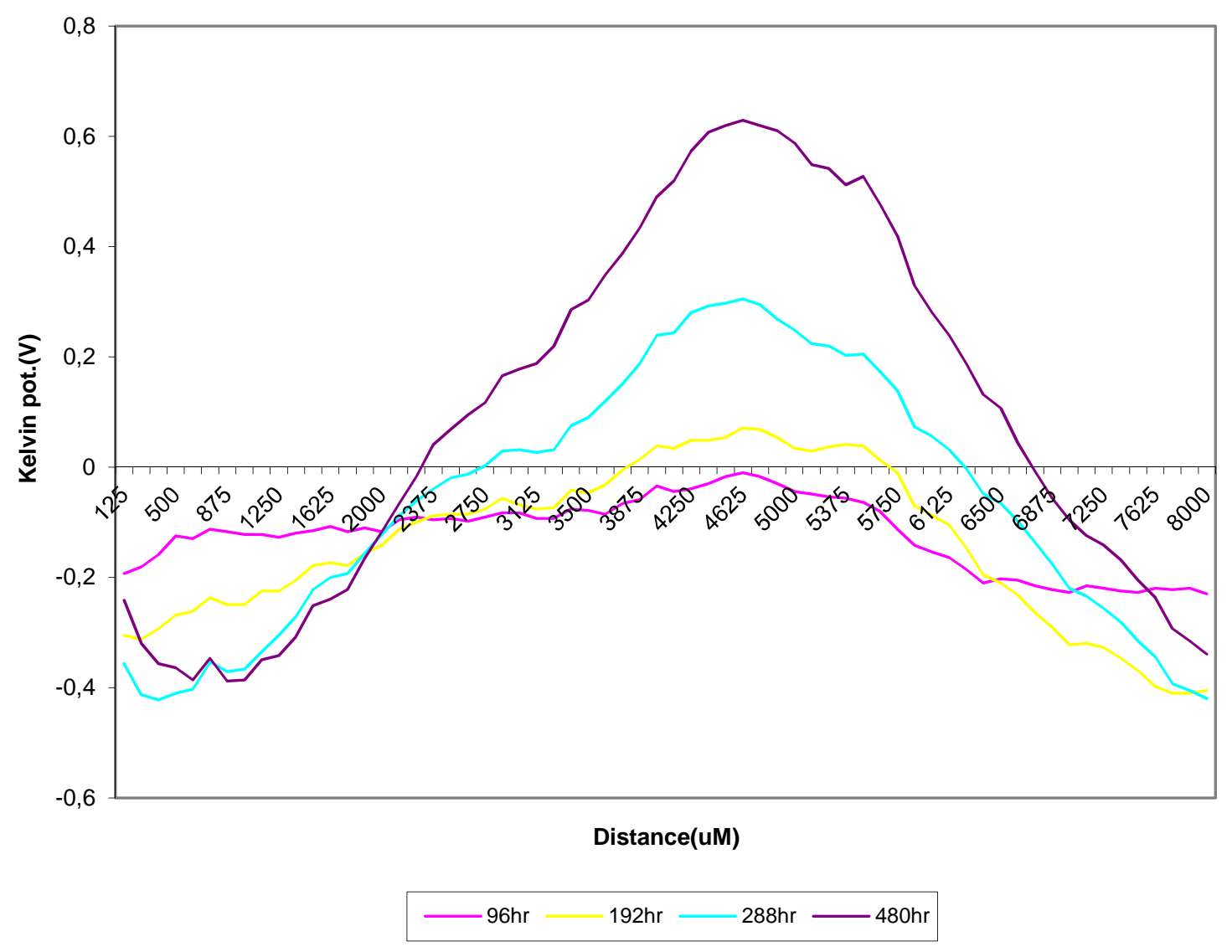

Fig.19. SKP line scan data for different exposure times with PVB (65 $\mu \mathrm{m}$ thickness) on mild steel substrate with a scratch defect through the coating into the substrate.

The ability of the instrument to measure the delamination of a smaller diameter defect was also investigated. The defect was a scalpel blade scratch on different thickness of PVB coating. The cases looked at were a $35 \mu \mathrm{m}$ and a $65 \mu \mathrm{m}$ thick PVB coating on a mild steel substrate. The SKP line scan data show a central peak for the defect and a gradual decrease from the peak on either side and a steady area away furthest from the defect. The data shows again three distinct regions exist for the corrosion cell. A region of intact coating (not delaminated from the substrate) with values close to steel in air, the delamination area on either side of the defect and a central peak for the defect (as previously for the hole defect). The defect has higher potential values and as the exposure time is increased the values increase. The instrument was able to detect the smaller diameter scratch and again follow the delamination with exposure time. Using the same substrate and the same coating, potential values observed are similar for the different PVB thicknesses, within experimental error. Comparing the $35 \mu \mathrm{m}$ and $65 \mu \mathrm{m}$ PVB coatings with scratch defect against the PVB thicknesses with the hole defect, it is observed that the values are similar. The instrument is shown to give reproducible and consistent values. 


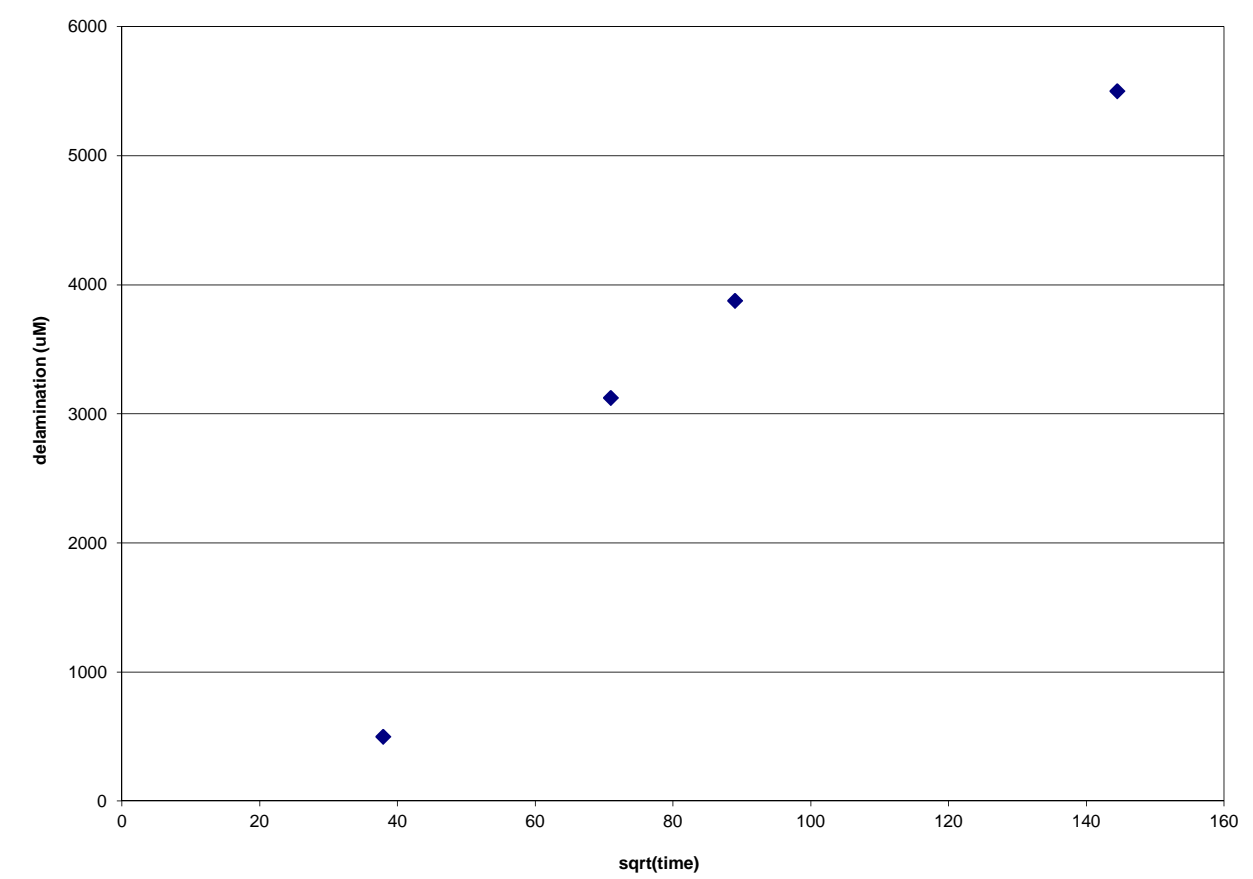

Fig.20. Plot showing the increase in delamination over exposure time with PVB $(35 \mu \mathrm{m}$ thickness) on mild steel substrate with a scalpel blade defect (100 $\mu \mathrm{m}$ in length) through the coating into the substrate.

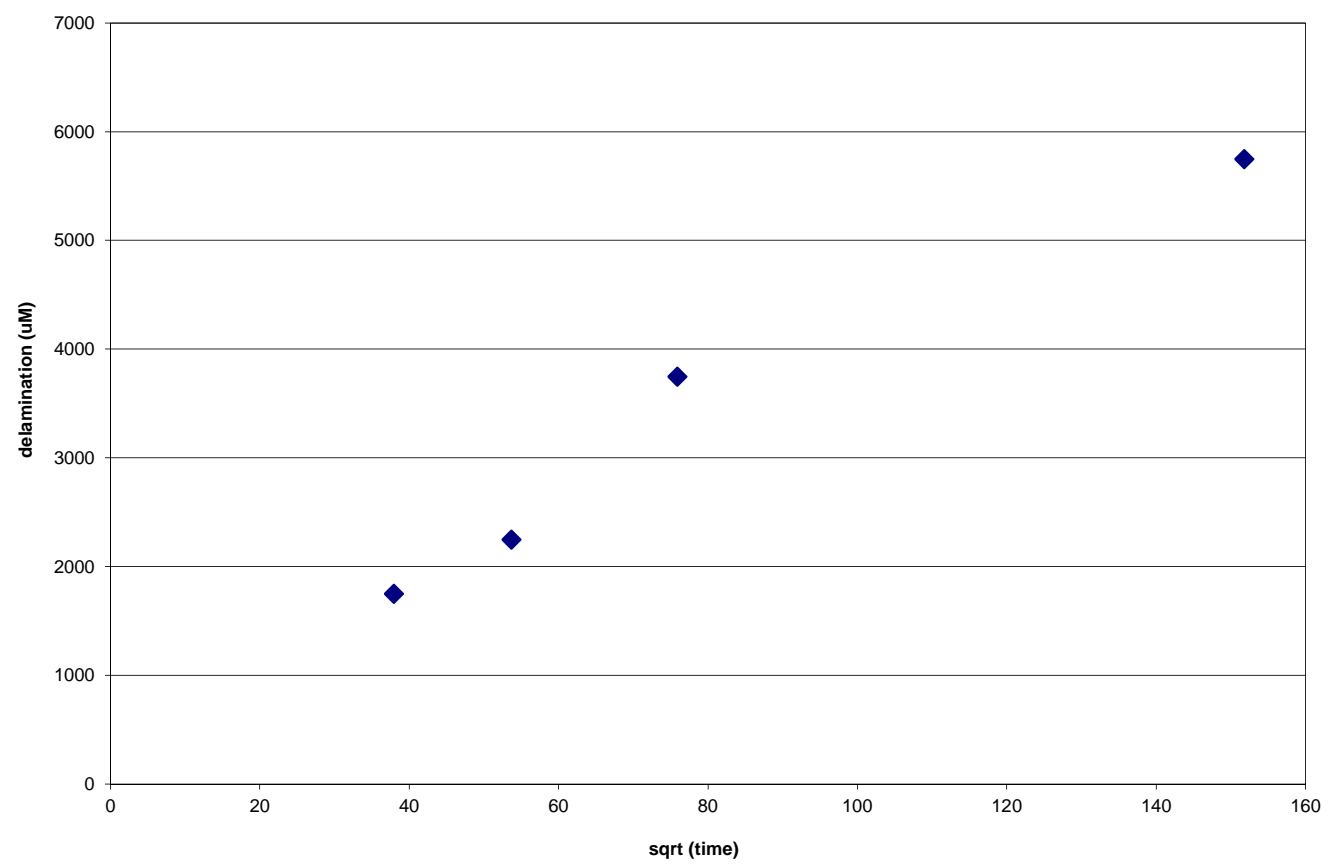

Fig. 21. Plot showing the increase in delamination over exposure time with PVB $(65 \mu \mathrm{m}$ thickness) on mild steel substrate with a scalpel blade defect (100 $\mu \mathrm{m}$ in length) through the coating into the substrate. 
These plots show that the instrument is able to detect the increase of delamination around a smaller diameter defect. The full width of the scratch is obtained at different exposure times and plotted against square root of exposure time. The delmaination rate again is proportional to the square root of time indicating a diffusion process. There is a 'delay time' as before, as it takes time for the anions to penetrate into the defect and cause ionic conductance, which is detected by the instrument

\section{PVB coated galvanised steel}

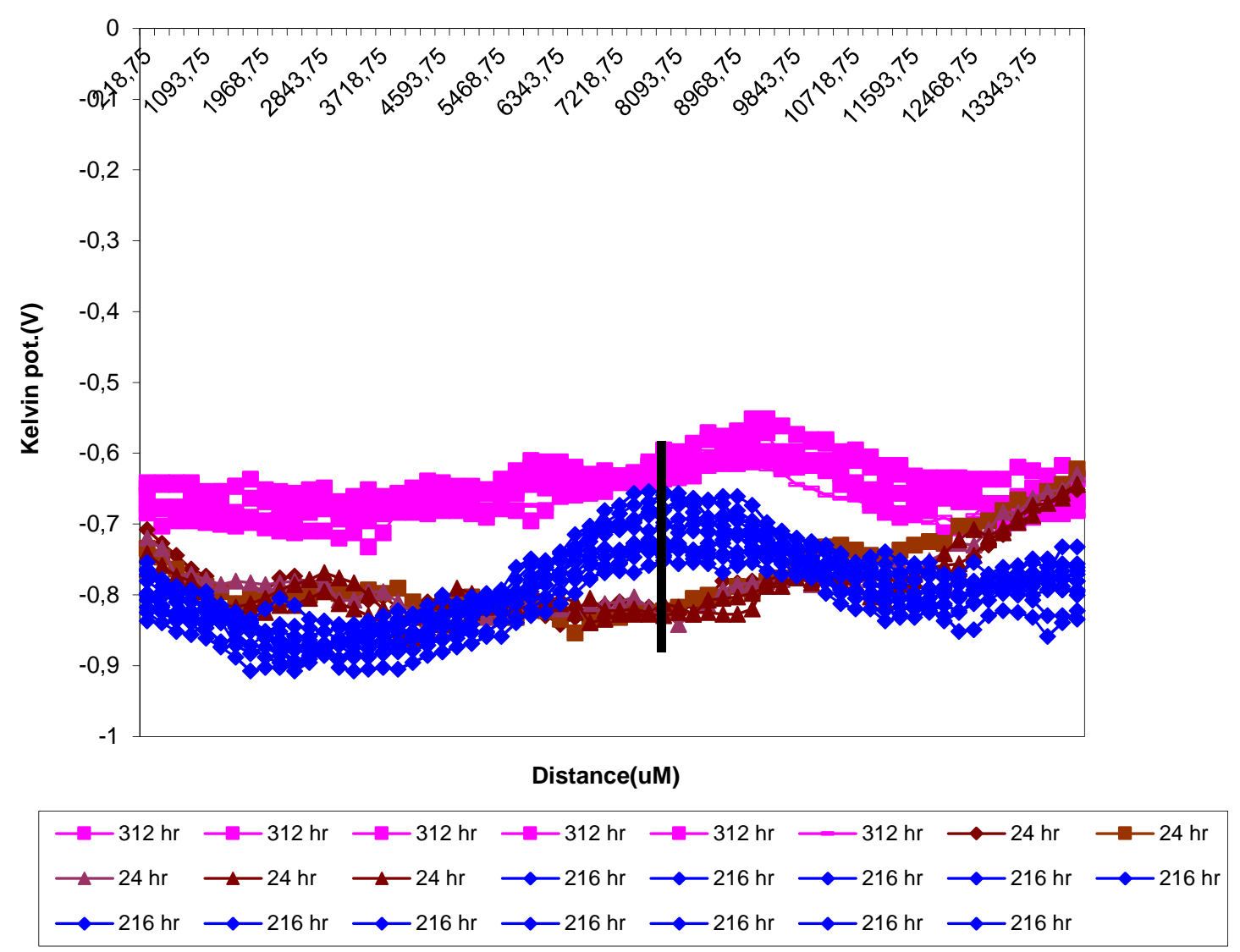

Fig.22. SKP line scan data for different exposure times with PVB (45 $\mu \mathrm{m}$ thickness) on galvanised steel substrate with a scratch defect through the coating into the substrate. A marker, on the diagram, highlights the location of the defect.

The SKP plot shows a scalpel blade scratch through a PVB coating on galvanised steel. Initially the potential is close to zinc as the zinc corrodes preferentially trying to protect the substrate from being attacked by the corrosive solution. After, a certain time the zinc is unable to protect 
the substrate and corrosion occurs. The potential stays negative with increased exposure due to the zinc. After, a certain time of exposure the delamination increases.

\section{Galvanised steel 'model' cut edge}

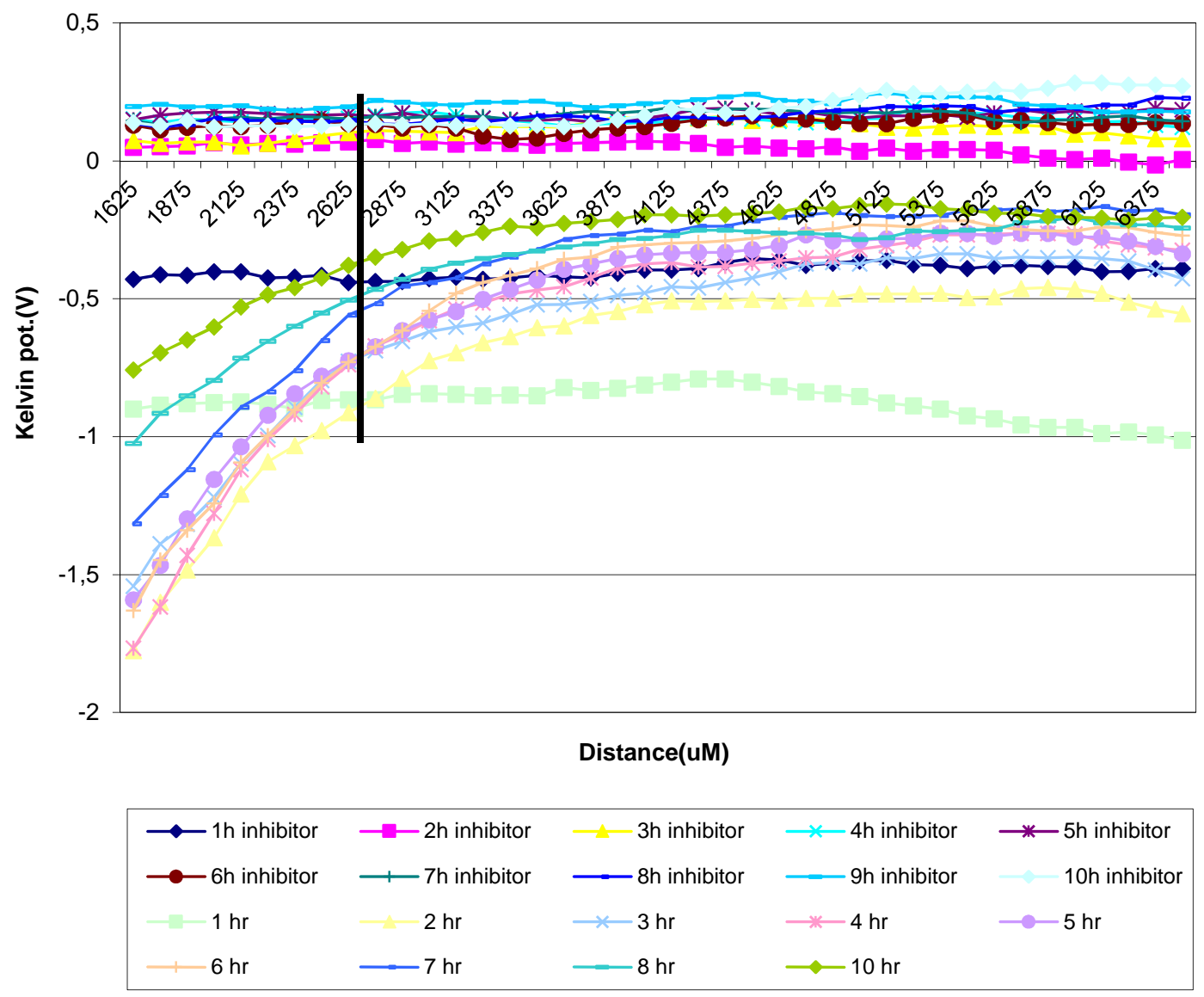

Fig.23. Plot showing the difference in potential measured by the SKP system with and without inhibitor added to the artificial acid rainwater solution. A marker, on the diagram, highlights the location of the edge.

The SKP plot shows the cut-edge and a small area on either side, which is the cured epoxy, keeping the cut edge fixed in position. The plot shows the potential measured by the SKP system with and without added inhibitor to the artificial acid rainwater solution over galvanised steel cut edge. A large difference in potential is observed by the SKP system with the addition of strontium chromate. Different area scans without the inhibitor show the potential is negative and stays constant over time, with the addition of the inhibitor the potential becomes positive and stays positive over time. The strontium chromate is an anodic inhibitor and causes the 
potential to become positive and makes the sample passive. The system is able to detect the change in potential over time.

\section{Epoxy coated galvanised steel with inhibitors}

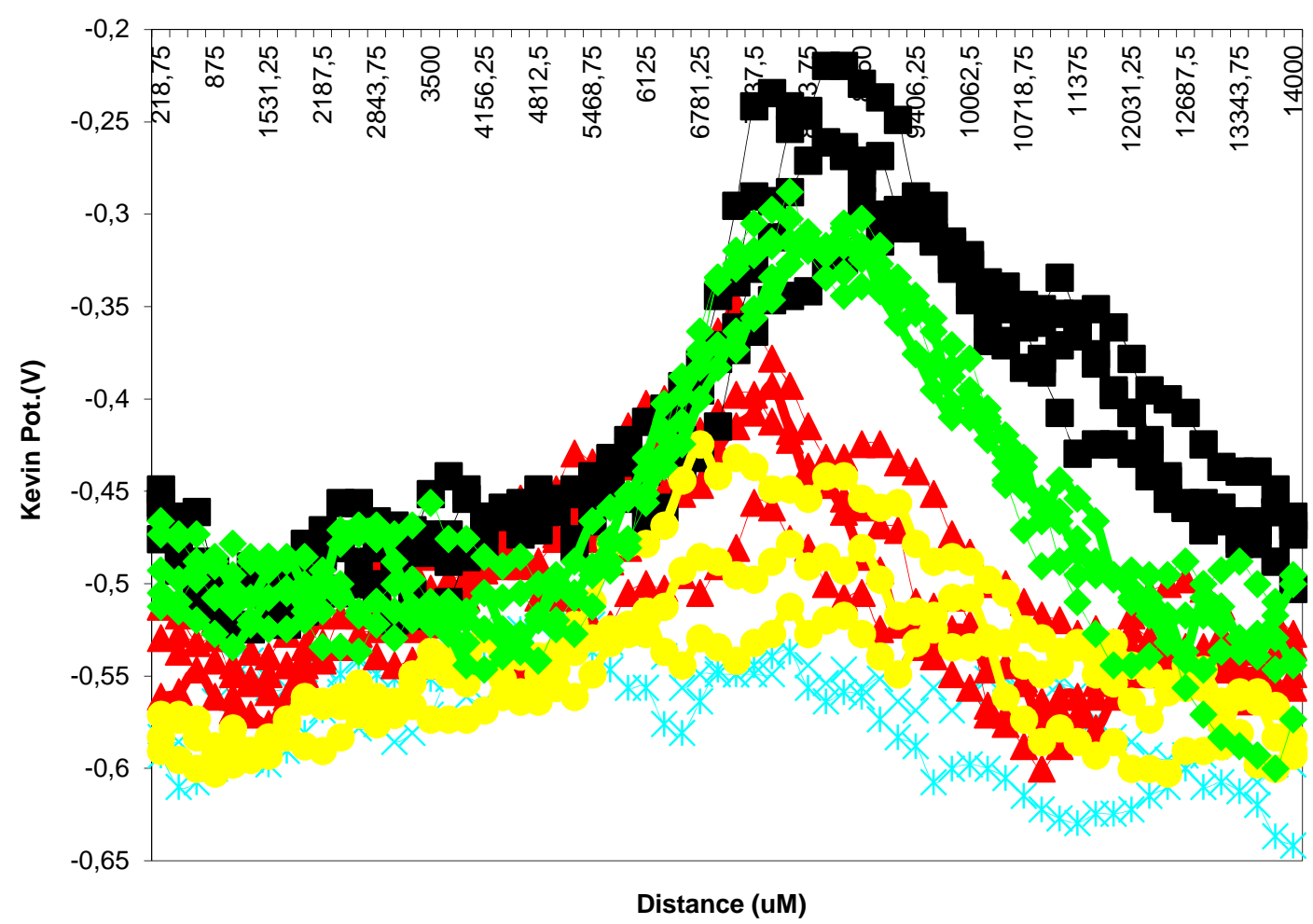

\begin{tabular}{|c|c|c|c|c|c|}
\hline$\times \quad E 17-24 \mathrm{hr}$ & * E17-24 hr & $-\Delta-\mathrm{E} 17-96 \mathrm{hr}$ & $\Longrightarrow \mathrm{E} 17-96 \mathrm{hr}$ & $\longrightarrow \mathrm{E} 17-96 \mathrm{hr}$ & $\longrightarrow \mathrm{E} 17-96 \mathrm{hr}$ \\
\hline —E17-288 hr & $\longrightarrow-\mathrm{E} 17-288 \mathrm{hr}$ & $\longrightarrow \mathrm{E} 17-288 \mathrm{hr}$ & —E17-288 hr & $=\mathrm{E} 17-360 \mathrm{hr}$ & $=\mathrm{E} 17-360 \mathrm{hr}$ \\
\hline $\mathrm{E} 17-360 \mathrm{hr}$ & $\rightarrow E 17-552 \mathrm{hr}$ & $\approx$ E17-552 hr & $\Longrightarrow E 17-552 \mathrm{hr}$ & $\rightarrow \mathrm{E} 17-552 \mathrm{hr}$ & $\rightarrow \mathrm{E} 17-552 \mathrm{hr}$ \\
\hline
\end{tabular}

Fig 24. SKP line scan data for hole defect $(0.5 \mathrm{~mm}$ diameter $)$, exposure in artificial acid rainwater solution, galvanised steel and epoxy two-pack coat (130 $\mu \mathrm{m}$ total dry thickness). E17 (strontium chromate $1.5 \mathrm{v} \%$ ).

The SKP line scan data shows a central peak for the defect and gradual decrease on either side showing delamination of the epoxy from the substrate and then it levels of furthest from the defect. The value of the intact epoxy coating is closer to zinc in air (- $0.6 \mathrm{~V}$ at $24 \mathrm{hr}$ exposure). The full width of the lines is increasing with increased exposure but there are also effects caused by the inhibitor, which are detected by the instrument. The values of potential are becoming positive with increased exposure, which are due to the strontium chromate, which is known to act as an anodic inhibitor increasing the potential of the sample making it more passive. 
Another significant part of the data is the fact that the delamination has decreased, which again can be attributed to the strontium chromate, and is detected by the instrument. The full width of the green lines is less than the full width of the black line; therefore the delamination has decreased because of the inhibitor. In the epoxy case the values are steadier at the intact coating part then compared to the PVB case probably due to the better adhesion properties of epoxy compared to PVB.

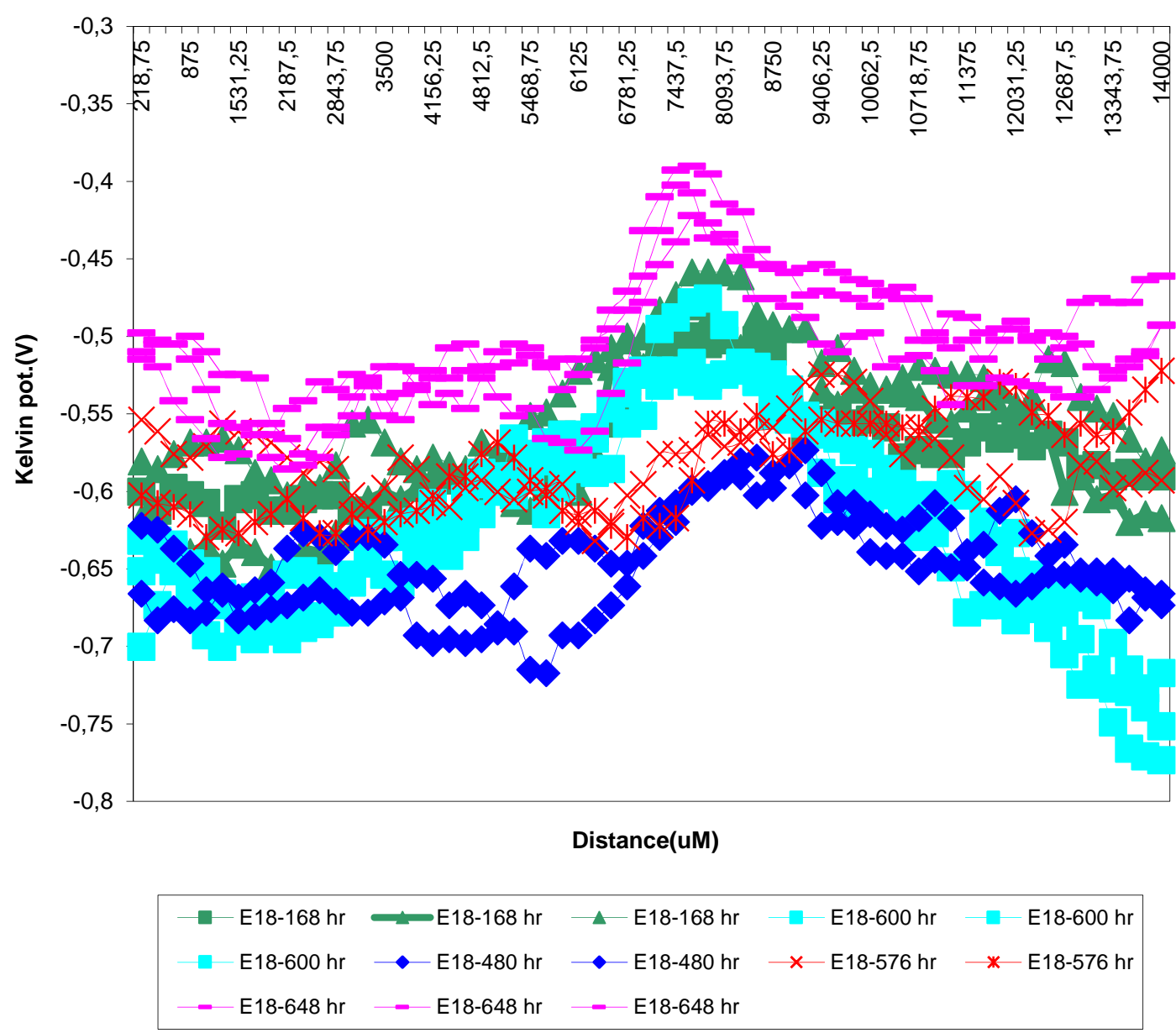

Fig 25. SKP line scan data for hole defect $(0.5 \mathrm{~mm}$ diameter $)$, exposure in artificial acid rainwater solution, galvanised steel and epoxy two-pack coat (130 $\mu \mathrm{m}$ total dry thickness). E18 (Actirox/Shieldex 4/4v\%).

The SKP plot shows the delamination rate of the hole defect with epoxy coating containing E18 (Actirox/Shieldex $4 / 4 \mathrm{v} \%$ ) as a viable replacement for strontium chromate as an inhibitor. The inhibitor has had effect on the delamination rate (width of blue line). At an exposure of $600 \mathrm{hrs}$ the full width of the line has decreased (measured by the full width of the lines) compared to the exposure at earlier times. The inhibitor has some effect in decreasing the delamination rate 
and also with greater exposure time there is also a shift in potential like the chromate before. The chromate has decreased the delamination faster compared to the Actirox/Shieldex inhibitor.

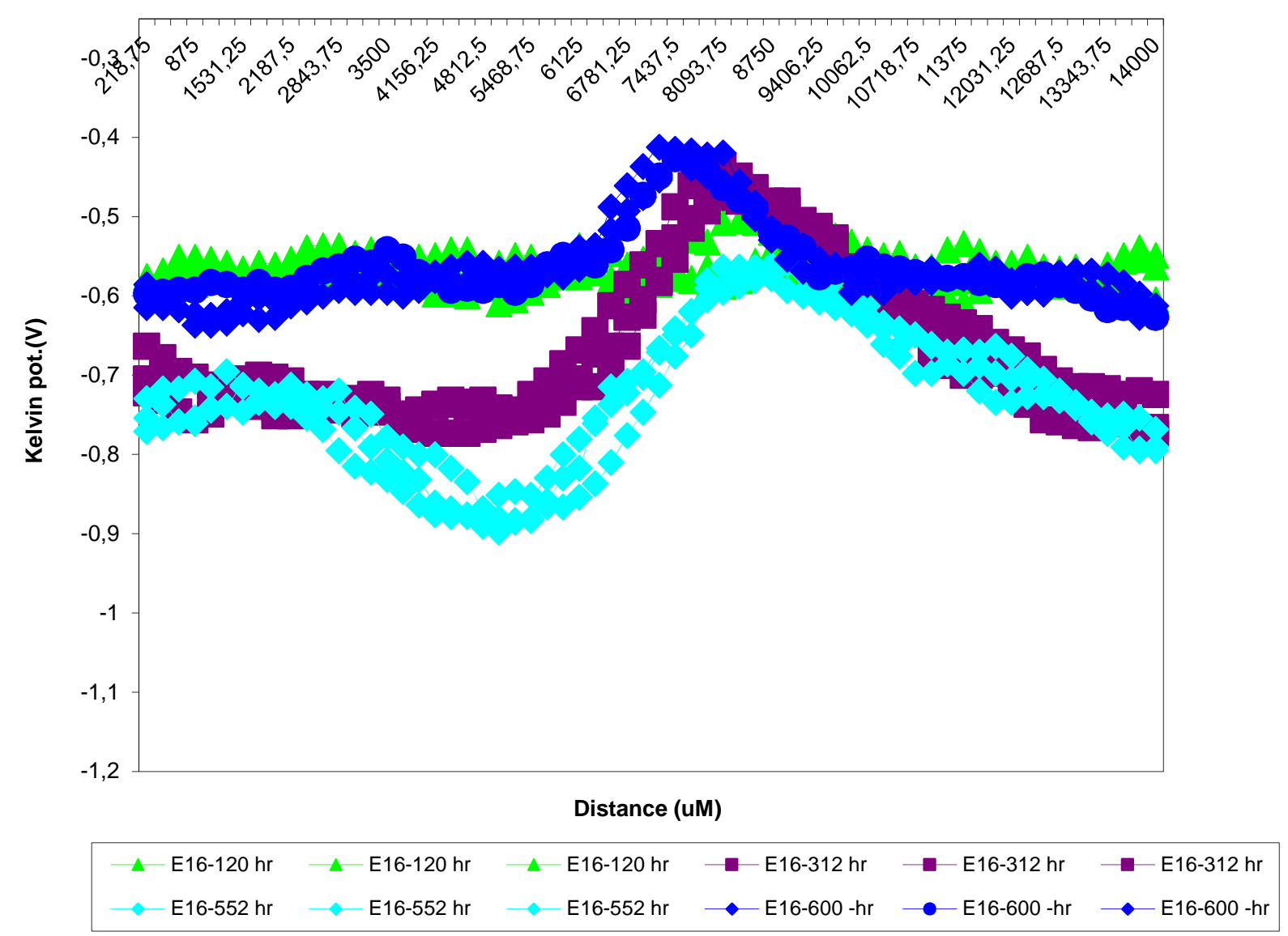

Fig. 26. SKP line scan data for hole defect $(0.5 \mathrm{~mm}$ diameter $)$, exposure in artificial acid rainwater solution, galvanised steel and epoxy two-pack coat (130 $\mu \mathrm{m}$ total dry thickness). E16 (Actirox/Shieldex 7/11v\%).

The graph plotted for E16 (Actirox/Shieldex $7 / 11 \mathrm{v} \%$ ) is very similar to the results presented for E18 (Actirox/Shieldex 4/4v\%). The width of the coloured lines decreases at high time of exposure (the delamination front of the defect). There is a shift of potential in the same range as for E18 (Actirox/Shieldex 4/4v\%). This shows the effect of the inhibitor again. 


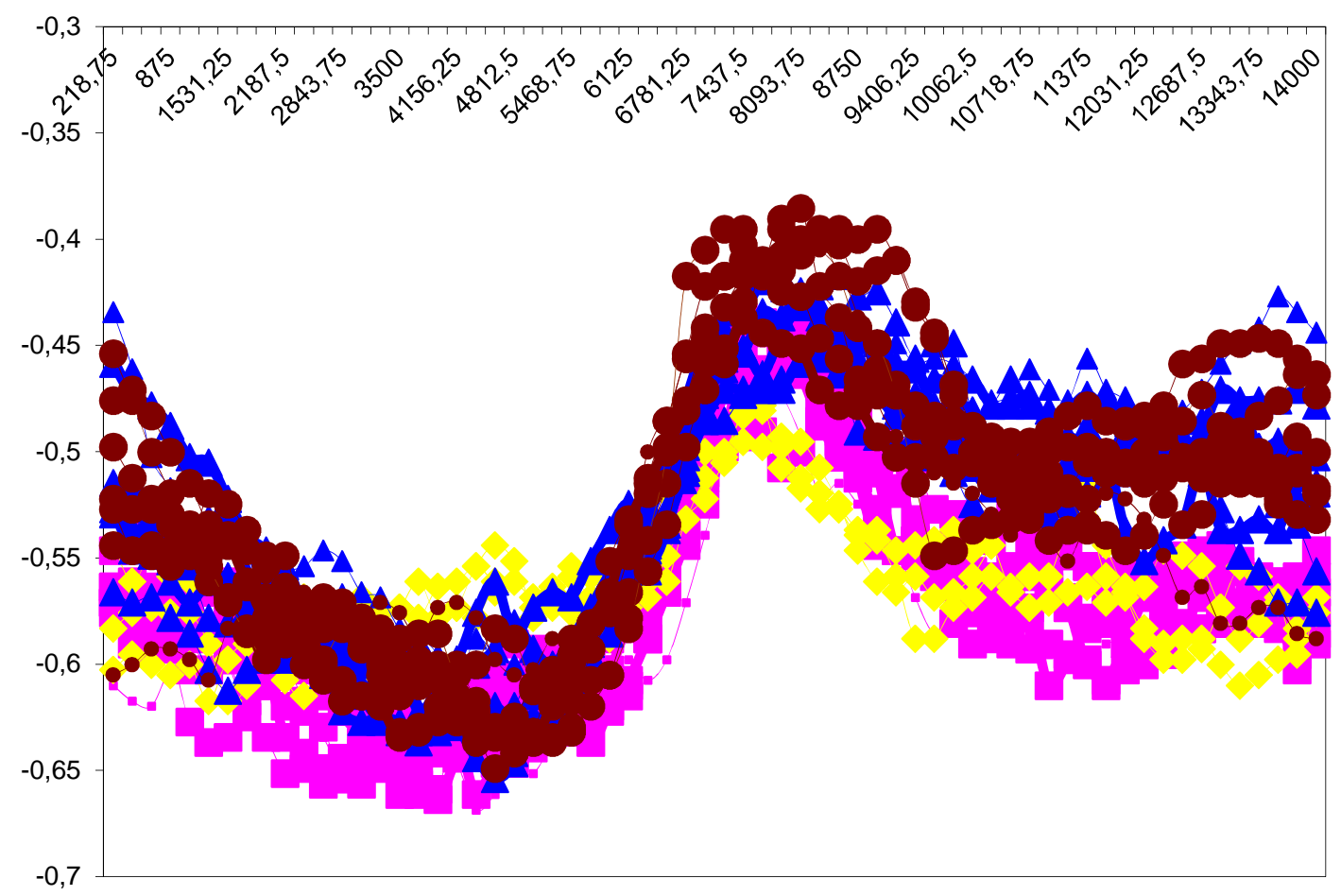

\begin{tabular}{|c|c|c|c|c|c|}
\hline$\longrightarrow E 8-24 \mathrm{hr}$ & $=E 8-24 \mathrm{hr}$ & $E 8-24 \mathrm{hr}$ & $=E 8-24 \mathrm{hr}$ & $=E 8-24 \mathrm{hr}$ & $=\mathrm{E} 8-24 \mathrm{hr}$ \\
\hline$=E 8-24 \mathrm{hr}$ & $\mathrm{E} 8-72 \mathrm{hr}$ & E8-72 hr & E8-72 hr & —E8-192 hr & -E8-192 hr \\
\hline -E8-1 & -E8-192 & E8-192 hr & — E8-192 hr & \ E8-192 hr & - E8-216 hr \\
\hline - E8-216 hr & - E8-216 hr & - E8-216 hr & - E8-216 hr & $\longrightarrow E 8-216 \mathrm{hr}$ & - E8-216 hr \\
\hline
\end{tabular}

Fig.27. SKP line scan data for hole defect $(0.5 \mathrm{~mm}$ diameter $)$, exposure in artificial acid rainwater solution, galvanised steel and epoxy two-pack coat (130 $\mu \mathrm{m}$ total dry thickness). E8 (Actirox/Shieldex 3/3v\%).

The sample E8 (Actirox/Shieldex 3/3v\%) has very little effect in suppressing the delamination of the epoxy coating from the substrate. 


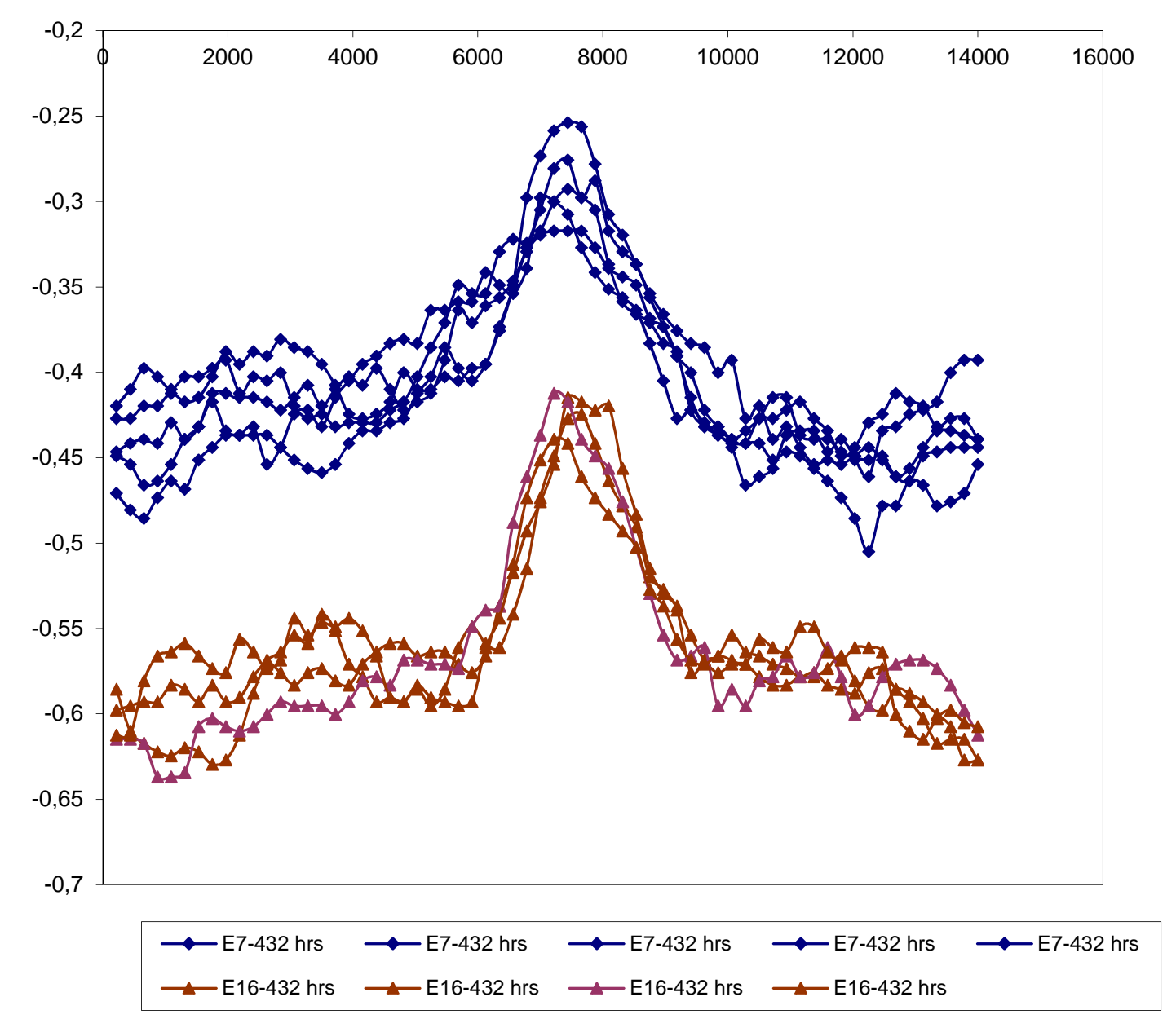

Fig.28. SKP line scan data for hole defect ( $0.5 \mathrm{~mm}$ diameter), rainwater galvanised steel, 432 hrs exposure. E7 $\left(\mathrm{TiO}_{2} 6 \mathrm{v} \%\right)$ and E16 (Actirox/Shieldex 7/11v\%).

$\mathrm{E} 7\left(\mathrm{TiO}_{2} 6 \mathrm{v} \%\right)$ is used as a control sample to compare the delamination rate with samples that have chromate as an inhibitor and those that have Actirox/Shieldex as inhibitor. Comparing the SKP data for the E7 $\left(\mathrm{TiO}_{2} 6 \mathrm{v} \%\right)$ and E16 (Actirox/Shieldex $7 / 11 \mathrm{v} \%$ ) shows the delamination rate (width of the coloured lines) to be pretty similar at same time of exposure. There has been some effect due to the Actirox/Shieldex as the width of the line has decreased.

E16 (Actirox/Shieldex 7/11v\%) has more negative potentials then $\mathrm{E} 7\left(\mathrm{TiO}_{2} 6 \mathrm{v} \%\right)$. There is some cathodic control of corrosion reaction inside of the defect area for the coating E16 (Actirox/Shieldex $7 / 11 \mathrm{v} \%$ ). This control can be caused by deposition of protective film of calcium and zinc phosphates. Corrosion is also developing faster for coatings without inhibiting pigments. E16 (Actirox/Shieldex $7 / 11 \mathrm{v} \%$ ) has more negative potentials away from defect as 
well. It can be because of better barrier properties of the pigmented coatings because phosphate pigments are less soluble than chromate (about 20 times).
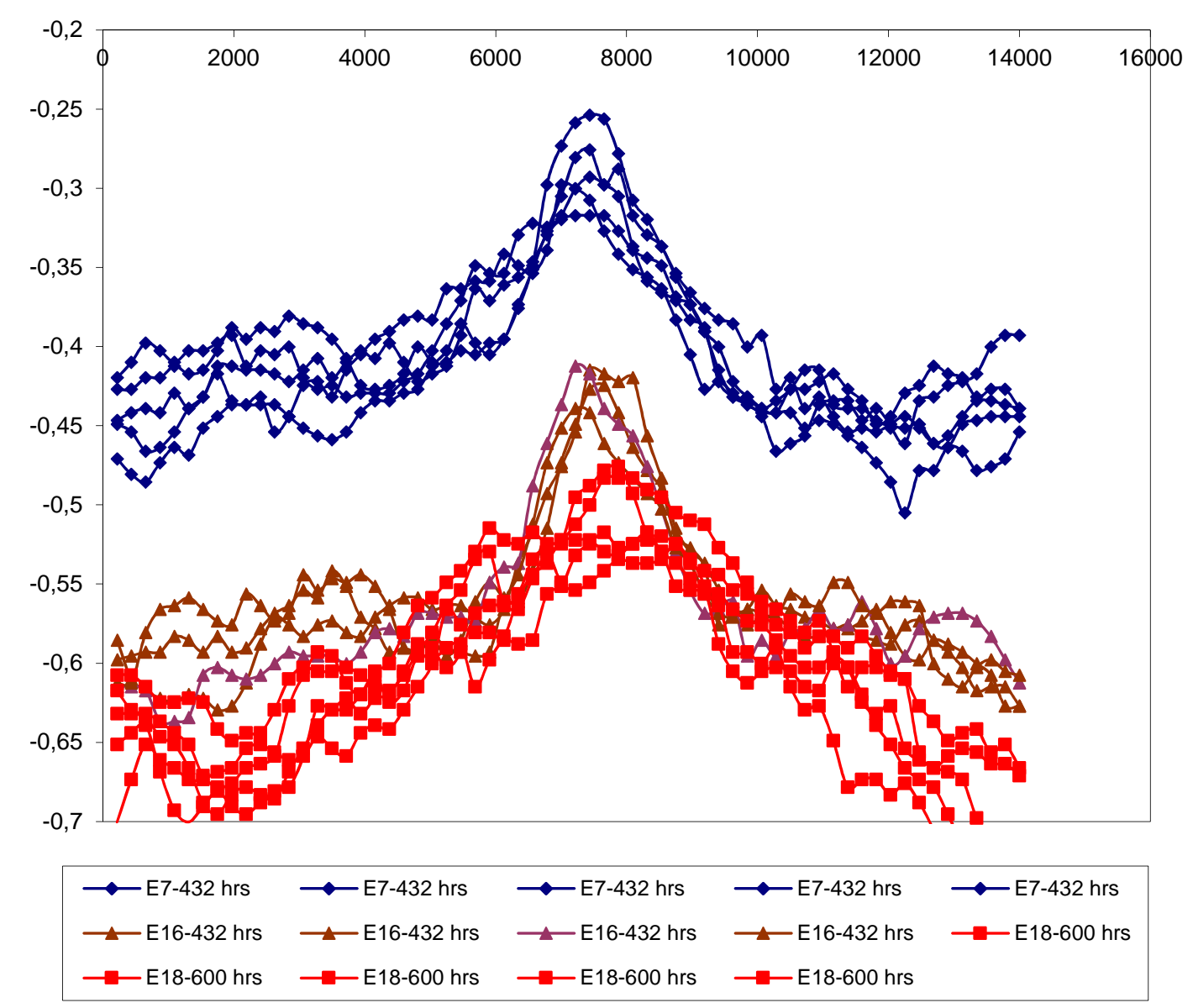

Fig.29. SKP line scan data for hole defect ( $0.5 \mathrm{~mm}$ diameter), rainwater galvanised steel, 432 hrs exposure. E7 $\left(\mathrm{TiO}_{2}\right.$ 6v\%), E16 (Actirox/Shieldex 7/11v\%) and E18 (Actirox/Shieldex $4 / 4 \mathrm{v} \%)$.

A comparison plot showing E7 $\left(\mathrm{TiO}_{2} 6 \mathrm{v} \%\right)$ and E16 (Actirox/Shieldex $7 / 11 \mathrm{v} \%$ ) and E18 (Actirox/Shieldex 4/4v\%) shows that E16 (Actirox/Shieldex 7/11v\%) and E18 (Actirox/Shieldex 4/4v\%) are very similar. E16 (Actirox/Shieldex 7/11v\%) has more negative potentials then $\mathrm{E} 7\left(\mathrm{TiO}_{2} 6 \mathrm{v} \%\right)$. It can be stated that there is some cathodic control of corrosion reaction inside of the defect area for E16 (Actirox/Shieldex 7/11v\%). This control can be caused by deposition of protective film of calcium and zinc phosphates. Corrosion is also developing faster for coatings without inhibiting pigments. E16 (Actirox/Shieldex 7/11v\%) has more negative potentials away from the defect as well. It is because of the better barrier properties of 
the pigmented coatings because phosphate pigments are less soluble than chromate (about 20 times).

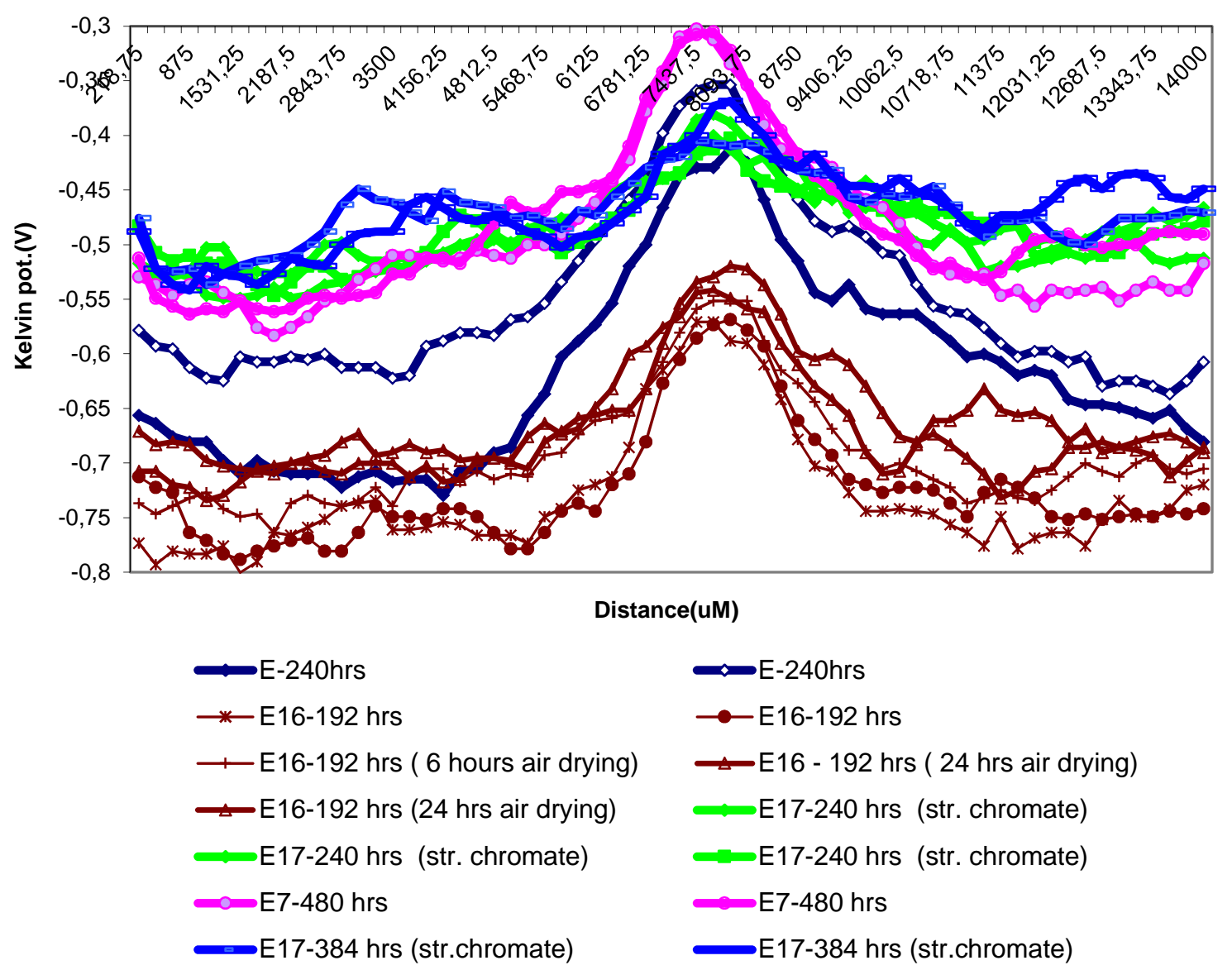

Fig.30. SKP line scan data for hole defect ( $0.5 \mathrm{~mm}$ diameter), rainwater galvanised steel, 432 hrs exposure. E (clear epoxy), E7 $\left(\mathrm{TiO}_{2} 6 \mathrm{v} \%\right)$, E16 (Actirox/Shieldex 7/11v\%) and E17 ( strontium chromate $1.5 \mathrm{v} \%)$.

The SKP data shows a comparison of results for the different inhibitors, in comparison to a control sample. E coating (epoxy) and $\mathrm{E} 7\left(\mathrm{TiO}_{2} 6 \mathrm{v} \%\right)$ have more positive potentials in the centre of the defect. Here the corrosion activity is developing and no significant inhibition occurs but some inhibition due to zinc ions deposited onto the cathodic surface and formation of zinc hydroxide. E16 (Actirox/Shieldex 7/11v\%) has more negative potentials then clear epoxy and $\mathrm{E} 7\left(\mathrm{TiO}_{2} 6 \mathrm{v} \%\right)$. This shows that there is some cathodic control of the corrosion reaction within the defect area for the E16 (Actirox/Shieldex 7/11v\%) case. This control can be caused by deposition of protective film of calcium and zinc phosphates. Corrosion is also developing 
faster for coatings without inhibiting pigments. E16 (Actirox/Shieldex 7/11v\%) has more negative potentials away from the defect as well.

E17 (strontium chromate $1.5 \mathrm{v} \%$ ) has relatively (if compare with the potentials for E17 away from hole) low potentials inside of hole (potential peak). Absolute values of potential for E17 (strontium chromate $1.5 \mathrm{v} \%$ ) are more positive than for E16 (Actirox/Shieldex $7 / 11 \mathrm{v} \%$ ). It is well known that chromate passivates steel, zinc and galvanised steel and moves their corrosion potential towards positive values. So corrosion of galvanised steel under coatings E17 (strontium chromate $1.5 \mathrm{v} \%$ ) (especially hole area) is under anodic control. It can also be observed that barrier properties of chromate containing coatings are less strong than that for E16 (Actirox/Shieldex 7/11v\%) case.

Higher solubility of strontium chromate can also influence the barrier properties of E17 (strontium chromate $1.5 \mathrm{v} \%$ ) and E17 (strontium chromate $1.5 \mathrm{v} \%$ ) corrosion potential outside of the hole. The instrument is able to detect the changes in potential due to the inhibition action of the added components. E17 (strontium chromate $1.5 \mathrm{v} \%$ ) has a great effect on the delamination rate as it acts like anodic inhibitor making the potential more positive, therefore decreasing the full width of the lines (delamination). E16 (Actirox/Shieldex 7/11v\%) has some effect but E17 (strontium chromate $1.5 \mathrm{v} \%$ ) is superior.

The Kelvin probe was used to detect the delamination of the organic coating in the vicinity of defects, which penetrate the coating. The corrosion properties are then investigated by different tests with changing climates, and the extent of delamination is analysed by mechanically removing the coating from the substrate. From an electrochemical point of view, an electrolyte layer covers the defect, an adherent polymer film increases the remaining surface, and on top of the coating an electrolyte is again situated. If however the Kelvin probe should investigate the electrochemical activity at the buried metal/polymer interface, then some electronic equilibrium between the buried interface and the polymer surface is required.

\section{CONCLUSIONS}

Kelvin probe is strictly an in situ tool, which detects the actual electrode potential of the buried interface being defined by the actual electrochemical reactions. It is not useful for investigating a dry sample, which had been corroded before, as the link between the electrochemical situation of the dry interface and the previous corrosion is not obvious. The system is able to distinguish the different areas of the defect, the central area in the area scan (red region) is the defect or local anode, either side of the defect delamination is observed (green region), which represents 
the failure of the coating as it has lost it's adhesion and finally furthest away on either side of the defect (blue region) the coating is intact and still adheres to the metal.

The system is able to detect the delamination of a $23 \mu \mathrm{m}$ PVB coat and also a thicker coating of $112 \mu \mathrm{m}$ on mild steel substrate. The system has been calibrated using the tungsten probe with known electrode couples; therefore, the probe is able to give the true electrode potential (corrosion potential) at the barrier interface. Over exposure time the change in the electrode potential is observed between the barrier interface as ionic conduction occurs with penetration of the solution. This causes a greater delamination of the coating from the substrate. This is observed as the full width of the red area, which increases with increased exposure. Having a thicker coating of PVB, it is observed that the potential is higher; this was also observed when using a thin film over molar solutions with the respective metals.

\section{BIBILIOGRAPHY}

[1] Chen C., Breslin C.B., Mansfeld F., Scanning Kelvin probe analysis of the potential distribution under small drops of electrolyte. In: Bonora PL, Deflorian F, editors. Electrochemical Methods in Corrosion Research Vi, Pts 1 and 2, vol. 289 - 2. Zurich Uetikon: Transtec Publications Ltd, 1998. p.181.

[2] Nazarov A., Thierry D., Electrochim. Acta 2004, Volume 49, pp. 2717 - 2724.

[3] Knight S.P., Salagaras M., Wythe A.M., De C.F., Davenport A.J., Trueman A.R., Corr. Sci. 2010, Volume 52, pp. 3855 - 3860.

[4] Muster T.H., Hughes A.E., Thompson G.E., Copper Distributions in Aluminium Alloys. New York: Nova, 2009.

[5] Blanc C., Freulon A., Lafont M.C., Kihn. Y., Mankowski G., Corr. Sci. 2006, Volume 48, pp. $3838-3851$.

[6] Birbilis N., Buchheit R.G., J. Electrochem. Soc. 2005, Volume 152, pp. B140 - B151.

[7] Chen G.S., Gao M., Wei R.P., Corro. 1996, Volume 52, pp. 8 - 15.

[8] Ilevbare G.O., Schneider O., Kelly R.G., Scully J.R.. J. Electrochem. Soc. 2004, Volume 151, pp. B453 - B464.

[9] Leblanc P., Frankel G.S., J. Electrochem. Soc. 2002, Volume 149, pp. B239 - B247.

[10] Liao C.M., Olive J.M., Gao M., Wei R.P., Corr. 1998, Volume 54, pp. 451 - 458.

[11] Park J.O., Paik C.H., Huang Y.H., Alkire R.C., J. Electrochem. Soc. 1999, Volume 146, pp. $517-523$.

[12] Hughes A.E., Boag A., Glenn A.M., McCulloch D., Muster T.H., Ryan C., Luo C., Zhou X., Thompson G.E., Corr. Sci. 2011, Volume 53, pp. 27 - 39. 
[13] Glenn A.M., Muster T.H., Luo C., Zhou X., Thompson G.E., Boag A., Hughes A.E., Corr. Sci. 2011, Volume 53, pp. 40 - 50.

[14] Hughes A., Muster T.H., Boag A., Glenn A.M., Luo C., Zhou X., Thompson G.E., McCulloch D., Corr. Sci. 2010, Volume 52, pp. 665 - 668.

[15] Boag A., Taylor R.J., Muster T.H., Goodman N., McCulloch D., Ryan C., Rout B., Jamieson D., Hughes A.E., Corr. Sci. 2010, Volume 52, pp. 90 - 103.

[16] Fu Q., Tang X., Cheng Y.F., Corr. Sci. 2009, Volume 51, pp. 186 - 190.

[17] Rohwerder M., Turcu F., Electrochim. Acta 2007, Volume 53, pp. 290 - 299.

[18] Jonsson M., Thierry D., LeBozec N., Corr. Sci. 2006, Volume 48, pp. 1193 - 1208.

[19] Williams G., McMurray H.N., J. Electrochem. Soc. 2001, Volume 148, pp. B377 B385.

[20] Williams G., McMurray H.N., Hayman D., Morgan P.C., Phys. Chem. Comm. 2001, Volume 4, pp. $26-31$.

How to cite this article

Hussain A, Haque Sk M. Scanning kelvin probe applied to localised corrosion. J Fundam Appl Sci. 2015, 7(1), 103-138. 